\title{
Training Our Bodies to Defend Ourselves: Self-defence Training as Embodied Learning
}

by

Marion Robinson

A thesis submitted to the Faculty of Graduate and Postdoctoral Affairs in partial fulfillment of the requirements for the degree of

Master of Arts

in

Anthropology

Carleton University

Ottawa, Ontario

(C) 2013, Marion Robinson 


\begin{abstract}
This thesis examines how self-defence training changes participants' experiences of, and responses to, lived vulnerability to interpersonal violence as seen through gender.

Fieldwork for this thesis took place in both an eight-week women's self-defence class and a twelve-week advanced (co-ed) self-defence class; taught by the same studio.

Participants in these classes cultivated a variety of body-habits that will be explored in terms of training perception; control over one's affective responses to threats; and control over aggressive/threatening situations as a whole.

While other studies of self-defence featuring women tend to focus on describing the benefits of the practice for female survivors of sexual violence, this study is broader in scope. It examines how these benefits come about through a phenomenological analysis of the habits taken up in self-defence training, and it offers commentary on how gender norms are addressed, taken up, or challenged through the practice of self-defence.
\end{abstract}




\section{Acknowledgements}

I would like to thank all of the people who have supported me through this research project: my research participants, without whose conversations and friendship, there would not be a project. My thesis advisor Bernhard Leistle deserves special thanks for his patience, his empathy, and his insights into habituation and learning. I would also like to thank my second reader Danielle Di Novelli-Lang, whose words were exactly what I needed to hear, when I needed to hear them. My friends Cassie Verardi, Megan Graham, Juhli Lyncaster, and Dave Tang, thank you for reminding me that my work is important enough not to give up on. I would also like to thank my brother Sean for his reminders that critique and compassion are not mutually exclusive. 


\section{Table of Contents}

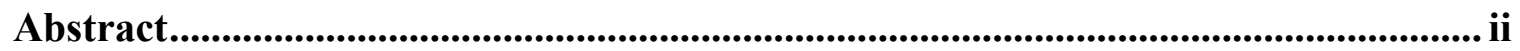

Acknowledgements ............................................................................................................................. iii

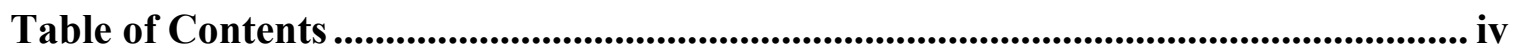

List of Tables ........................................................................................................................... v

List of Illustrations...................................................................................................................... v

1 Chapter: Introduction ......................................................................................................... 1

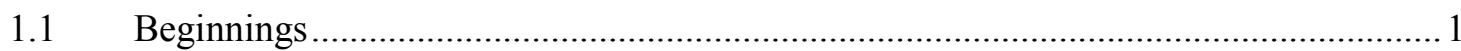

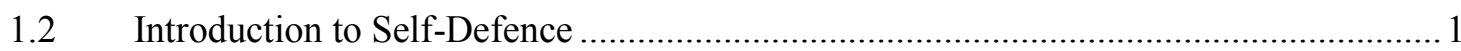

$1.3 \quad$ Apprenticeship and Methodology ……………………………………………..

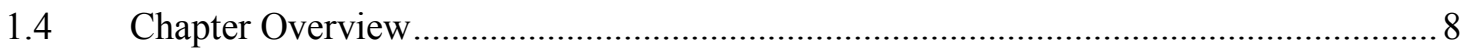

2 Chapter: Embodied Learning and Self-Defence......................................................... 11

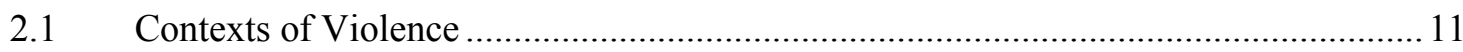

2.2 Self-Defence and Martial Arts in Response to Vulnerability:....................................... 19

2.2.1 Martial Arts as Self-Defence: Training Perception.................................................2 20

2.2.2 The Benefit and Problem of Self-Defence Itself.......................................................2

2.3 The Body in Motion: Phenomenological Anthropology …………………………......2 29

2.4 Self-Defence from a Phenomenological Point of View ……………………………....32

2.4.1 Learning Through the Body as Process and Problem ................................................4 41

3 Chapter: Perceptions of Vulnerability and Violence................................................. 46

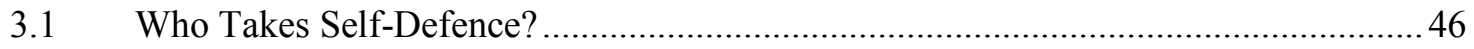

3.2 Into the Field of Self-Defence .............................................................................

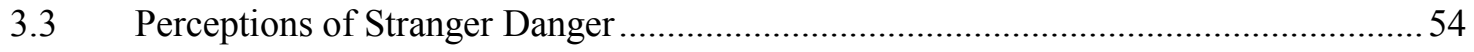

3.4 The Gift of Fear: Understanding the Signals of Vulnerability to Violence....................60 
3.4.1 Responding to the Signals of Violence and Vulnerability

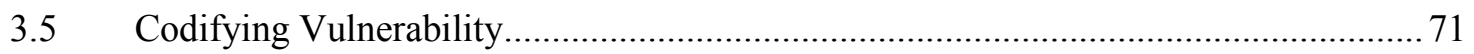

3.5.1 Coping with Vulnerability: Framing an Aggressor's Actions................................... 80

4 Chapter: Interruptions of Vulnerability ...................................................... 83

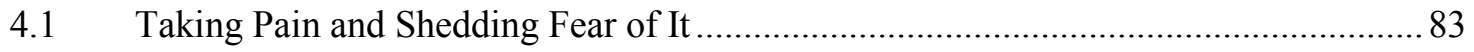

4.2 Dishing Out Pain: From Aversion to 'Do What You Have To' .................................... 89

4.3 Managing Aggression and its Impressions ........................................................ 95

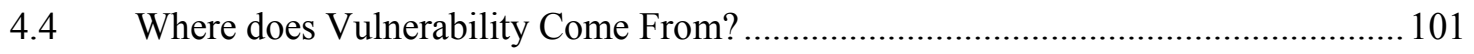

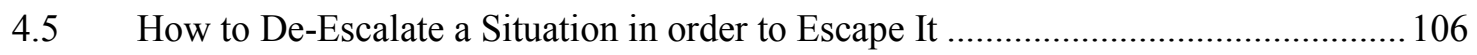

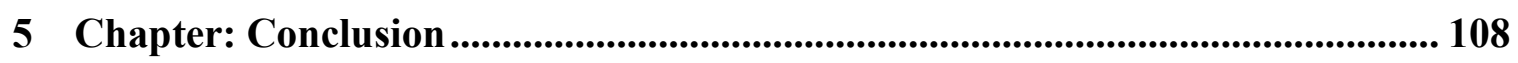

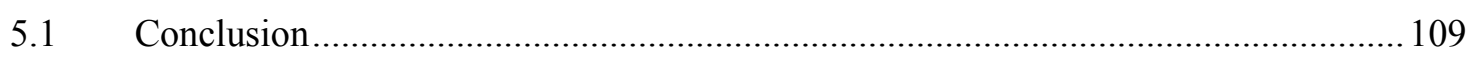

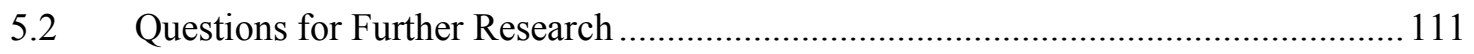

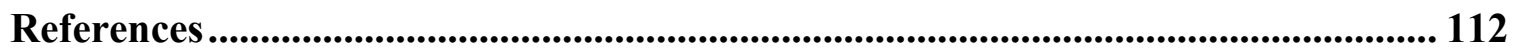

\section{List of Tables}

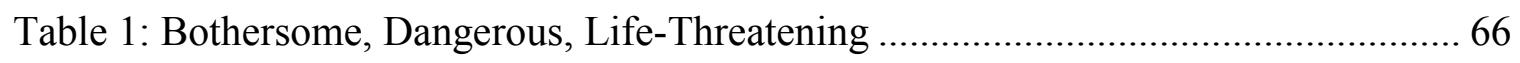

\section{List of Illustrations}

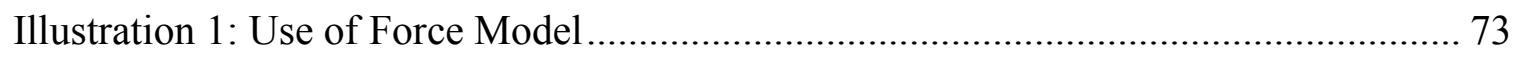




\section{Chapter: Introduction}

\subsection{Beginnings}

This project, though it officially began with an inquiry into self-defence as a response to violence against women, actually has older beginnings along similar, albeit more personal, lines. It began not with self-defence, but with martial arts, which I began at age eleven, because my family felt such arts to be 'a natural response' to bullying and violence. Over the years of training, of continuing to deal with bullying, and finally of dealing with a particular bully in a decidedly un-martial-artist-like manner, a question came up again and again. It started with a question my parents did not ask when enrolling me into karate: 'does training in martial arts work to prevent further violence, or not?' This project is an extended examination into a much more refined question than simply ‘do martial arts or self-defence work?' My inquiry begins anew with asking how. How do martial arts and self-defence work on the bodies of their participants?

Before I begin, I want to highlight orthography and use of pronouns - where a given practice could be used by both men and women, I use the plural forms (their, themselves) interchangeably with 'his or her' to work around one of the limits of the English language - we do not have a second or third-person common-gendered pronoun. This might not be ideal, but it is one of the ways of working around gender biased language recommended by the American Anthropological Association (AAA Style Guide 2009: 4). I should also note that I tend to use field notes in an illustrative manner for either topical or theoretical points. With this said, now let us introduce self-defence.

\subsection{Introduction to Self-Defence}


Self-defence training changes how participants experience and respond to potential or ongoing violence in their lives, by training them in three 'streams' of bodily knowledge:

- Perception, or attending to one's surroundings, to the behaviours of potential aggressors, and finally attending to one's own bodily responses to threats;

- Self-control, literally control over one's responses to a would-be attacker, whether by mitigating one's own aggression, or by being able to endure pain and not be intimidated by an aggressor;

- Physical techniques; or the movements for which self-defence is best known and most often conflated with being in its entirety as a practice.

The promise of self-defence training is that a practitioner will learn not only specific techniques with which to respond to unambiguously violent or threatening situations, but also how to pay attention to both her own bodily responses, and the cues given off by an aggressor in a potentially threatening situation. Through such training, participants learn both particular ways of paying attention to their surroundings, to their own fight-or-flight responses, and to give those responses credence rather than questioning or silencing them. This approach to re-training a person begins somewhere between the habits imposed upon the body through the discipline of training, and the language used to communicate how to take up these new habits. As such, it offers the potential to recreate the person as someone who, instead of acquiescing in the face of a threatening situation, will respond effectively to protect his or her self. The premise and promise, then, of selfdefence training, is in learning how to use the body's own protective mechanisms, and use them effectively in both addressing immediate threats and deterring future ones. 
I locate my study at an intersection of feminist sociology of self-defence as response to gender-based violence, and anthropological inquiry into gender and the body in motion, as seen through studies of martial arts. The self-defence/martial arts link is key to my project, because martial arts practice tends to focus on changing the way a person relates to their own bodily responses to the world - and to others - around them. Martial artists train intensively for years, covering physical practices, meditation, and verbal exercises intended to encourage a practitioner to reflect on, or change, some habit or way of viewing and solving problems. One of the main goals of martial arts practice tends to be 'changing the body to change the mind', and self-defence practice aims towards a similar goal, using pedagogy often borrowed from martial arts.

Processually, it would look like the following: through the development of technical skills specific to self-defence, both physical and affective/emotional, trainees learn to interrupt that personal sense of vulnerability otherwise developed through socialization. By developing both physical and emotional toughness, the trainee can develop the fundamental sense of a right to defend themselves, to develop boundaries, and enforce them. The aim of self-defence, then, is to provide a toolkit which can be used creatively to enact and enforce boundaries in a particular way.

Self-defence training approaches this dialectic in a variety of ways: Courses such as Model Mugging or the Rape Aggression Defence System (RAD program) are designed to offer participants a toolkit of specific situational responses in as short a time as possible - usually one or two 8-hour days of training. Such courses may touch on violence as a social problem, but the constraints of time available do not allow for deeper exploration of this, or for how participants can change their responses to a world of 
potential risk in a more general way. Longer-term courses mimic martial arts training, in that they offer participants the potential for a deeper transformation of self through training the body: from operationalized awareness levels, to responses to threatening situations, to developing the physical capability to respond to those situations, and finally developing new responses to the world, conceived of as a space of potential risk. I took two self-defence courses which spread from June to November of 2012. The women's course ran for eight weeks, at one hour per class during the summer, and included The Gift of Fear and Other Survival Signals that Protect Us from Violence by Gavin de Becker, as well as other assertiveness-training handouts. The advanced selfdefence course ran for twelve weeks during the fall, at ninety minutes a class per week, and included handouts excerpted from Canadian security personnel training manuals such as the Canadian Use of Force System.

Both mimicked martial arts training in that not only did they take longer than a RAD or Model Mugging-style course to complete, but they focused on the dynamics of the self-other relationship, rather than on a small toolkit of situational techniques designed to address only specific types of gender-based violence (usually dating violence or sexual harassment).

Each course approached this wider dynamic of interpersonal violence differently. The women's course tended to examine violence as a social problem, while focusing on the dynamics of intimate partner or gender-based violence. The advanced course focused more on practical responses to interpersonal violence by training physical techniques borrowed from the security, military, and policing professions. 
Both courses aimed to achieve some of the changes possible within a martial-arts framework, but in shorter time. Each course focused on a few aspects of the self-other relationship, such as 'how the self responds to the threat or reality of interpersonal violence'; 'how to (de)escalate a conflict'; and 'how to manage one's emotive or affective responses to aggression'.

\subsection{Apprenticeship and Methodology}

Before I discuss the methodology of my project, let me first introduce Jaida Kim Samudra's 2008 work on White Crane silat, which highlights the challenges of translating kinaesthetic experiences into words or visual representations for scholarly purposes. Samudra argues for participation and apprenticeship as a mode of ethnographic inquiry, stating that for many of the research participants themselves, she found that they could not believe her seriousness about the topic until she participated and learned the Silat forms. Moreover, Samudra found through her participation, that she could:

“...conduct somatic 'interviews' in parallel with verbal ones as [she tested her] increasing bodily knowledge against others, by 'asking' with her body, 'what do you mean by...? Show me...? Teach me...?' The consultant then demonstrates the movement or corrects the form of the anthropologist's body. When other consultants do the same thing in response to the same query, the anthropologist begins to understand cross-body knowledge. One may eventually correlate culture-specific terms to bodily actions, thus developing greater precision in coding one's written field notes" (Samudra 2008: 670).

Her methodological emphasis, then, is on sharing social experience, rather than interpreting social discourse (Samudra 2008: 667). It is this mode of doing research that I found most fruitful, given that my spoken-word interviews were fewer than the 'somatic interviews' that took place in both of the self-defence classes I took, particularly in the advanced class, where doing overshadowed talking. 
If phenomenology is the study of lived experience, and embodiment is a methodological field for what one does with the body, then it makes sense to weave theory, methodology, and ethnography together. This was the basis for my study: participant-observation of five months of self-defence classes, including several informal conversations about self-defence, what brought the participants to take or teach selfdefence, and eventually five semi-structured interviews, two of which were with instructors (for the women's course and the advanced course, respectively) and the other three of which were with students. Samudra's 'somatic interviews' came up as a methodological practice for my work as well, given the relative difficulty of taking notes in a self-defence class or stopping to ask why move in a particular way with each technique we learned.

At the beginning of the women's and advanced classes, I explained the study and provided my consent letter for interested participants to refer to. The letter outlined the research, asked for participation, outlined the potential risks and benefits to the participants, and gave assurance that all collected information would remain confidential. In the letter, I also gave participants the option of whether to allow interviews to be audio-recorded or have me take notes instead, and also information on how to contact me or my supervisor. Those who agreed to participate and be interviewed signed the consent form, and while a total of eight people signed the consent form between the women's and advanced classes, three from the women's class dropped out before I could arrange to sit and talk with them about their experiences with self-defence and what brought them to take the class. As such, most of my interview or conversation material comes from 
participation in the classes, with many conversations taking place on the margins; before classes began, or on the walks and bus rides home.

It strikes me that I could have done with less 'structure' in the interviews - the ones which were most fruitful were with the students, particularly where we focused on one question or topic, such as confidence-building, or 'feelings of safety or danger' rather than trying to push through a schedule of questions. There were some reading materials associated with each class: Gavin De Becker's Gift of Fear and the Canadian Use of Force System guide, as well as various handouts - an assertiveness-training handout in the women's class, and some handouts on use of force, self-defence, and the Canadian criminal code in the advanced class. The readings lend themselves again very well to phenomenological frameworks, although a future researcher could do discourse analysis on the pieces themselves, or on the use of such readings in self-defence courses as a project in itself. Since my focus was on the experience of self-defence training and on use of such training on the ground, my use of these readings was to focus on their pragmatic implications - specific techniques offered in Gavin De Becker's book for attending to both one's bodily cues and one's surroundings, for instance; or 'how to look confident' from the assertiveness-training handouts, or how to both deal with and talk about a violent situation in a way intelligible to law enforcement (by following the cycle of threat/Canadian Use of Force System). I should note that although I will be treating the written materials (particularly De Becker's book) as ethnographic/primary sources, they will still be cited and referenced as published material.

I should also highlight the temporal aspect of the self-defence classes - by this I mean that while even a longer-term self-defence class cannot necessarily accomplish the 
re-habituation towards the world that many years of martial arts practice can, there is enough elapsed time to effect some changes in response to one's world - or at least one's own sense of vulnerability with regards to particular situations - say, harassment in public. The chapters as I have set them up, while they will attend largely to a given theme, will reflect this temporality where possible, in the sense that some themes or field experiences will be revisited in later chapters from a different perspective, likely one that came up later in the research, either in an interview or in the writing process. There is one more point that I will touch on briefly, and it is a question of who is represented in these studies. Much of the scholarship I review on women in self-defence tends to highlight white, upper-middle class, college-age women. The various scholars I review do offer the caveat that this is not representative of all western women, and then continue their analysis of 'women' in general, as if the women they acknowledge as 'not default' were, after all, default or representative of all women, period. While my study was conducted with fellow whites, many firmly middle-class and able-bodied, I want to try to help keep in mind that the experiences of these people are not the default for women at large white women experience vulnerability in a particular way, and again particular to class.

\subsection{Chapter Overview}

In the second chapter, I begin with a review of three streams of topical scholarship: anthropological and sociological studies of both gender-based and interpersonal violence, with a view to understanding the dynamics that create and sustain a sociocultural context of violence and vulnerability; anthropology of the body in motion as seen through martial arts, which tends to highlight the dynamics between the different practices taken up, 
habituation of the body, and addressing interpersonal violence; and feminist sociology of self-defence as it applies in particular to the women who might take self-defence, sometimes following an assault, sometimes in the spirit of prevention.

I also review one stream of literature that provides the backbone of the theory: phenomenology, as methodology for understanding such physical practices, and as the primary vehicle for my critique of both self-defence and the overenthusiasm of those academic scholars of self-defence as a response to violence or lived vulnerability, particularly where women are concerned. My critique also extends to habituation as a process - it takes a long time to develop a full range of habits, and self-defence classes, even extended into several weeks, can only 'open the door' to developing new habits not guide a participant through developing them completely, as in a long-term practice such as martial arts. These questions of habituation and the dynamics between violence and vulnerability will come up again throughout the thesis, but they are introduced as problems here.

In the first half of third chapter, I introduce the field and discuss the slippages between who takes self-defence and who is presented as doing so in both popular and academic discourse. In the second half, I discuss what I believe to be the first area of body-habits trained in a self-defence class: perception, beginning with how participants perceive the threats they face in their everyday lives, and training new modes of attending to those threats.

In the fourth chapter, I discuss the notion of self-control as seen through control over one's bodily responses to an attacker - most notably physical or emotional pain, and through control of one's own aggression or at least its appearance in defending oneself. 
This 'aggression/impression-management' has implications both in terms of genderperformance, and in more general socio-legal terms, although I attend with greater detail to the gender question, making some comments on how traditional gender performances create hidden vulnerability for men and women alike; and making note of some of the means by which self-defence participants subvert these norms, and also escape situations of ongoing violence in their lives.

In the conclusion, I draw the threads together to say that self-defence offers participants some new avenues to explore their relationship to violence and vulnerability, and helps develop some responses to specific situations, but ultimately the project of selfdefence is one that must be taken up as an ongoing practice in order to fully realize its benefits. Some of the questions that came up in the course of my fieldwork are asked (if not answered) here, as questions for future research - specifically how gender performances create the conditions for panic in a confrontation, or what the dynamics are between aggression/impression-management and defence of the socio-legal self. 


\section{Chapter: Embodied Learning and Self-Defence}

\subsection{Contexts of Violence}

Before I discuss the theories themselves of the dynamics between vulnerability and violence; or the ways in which martial arts or self-defence practice are taken up to address these on the ground, I will make a few bold statements based on my understanding from my research, which I will then follow up with the literature review that formed the basis of this understanding.

Self-defence can be an embodied response to potential or ongoing violence in participants' lives, such that they may be responding to past experiences, or may just be being proactive about their own safety. They may be attempting to find a way out of an abusive situation, and hoping the classes will give them some of the tools for doing so. They may be using the physicality of the practice as a path to healing from trauma.

At the same time, however, it strikes me that there is a wider discussion to be had here: one of vulnerability (towards violence) in general, which I would describe as a slippage between public discourse and lived realities of violence.

For women, this means a wide range of public discourses mainly surrounding women's presence in public spaces: 'stranger-danger', acquaintance rape, and whether women should be out late at night, for example. At the intersection of these discourses with a lived reality of most of the violence women face coming from people they already know, in private spaces, creates a dual vulnerability: both in that it focuses women's attention on the areas of their life where they are generally less likely to suffer violence, and in that it turns them away from attending to those areas of their life where they are more likely to suffer violence: their relationships. 
For men, this vulnerability stems from both a lack of public discourse about the ways in which they are vulnerable to violence (usually in public spaces, from other men, typically strangers), and from men's socialization into displays of aggression, where aggression becomes part of gender performance.

I will briefly cover anthropological definitions of violence as they give a view of violence in social/cultural context, and then bring focus onto women's everyday experiences of violence and negotiations of safety on the interpersonal level, particularly insofar as some of the questions raised by scholars studying violence can be addressed on the ethnographic ground. Some of the classes I took tried to address such questions as whether violent events can be interrupted at critical moments, as suggested in the work of Randall Collins, which will be examined here.

David Riches' 1986 work entitled “The Phenomenon of Violence”, continues to underpin the definitions used by scholars of violence in its political, interpersonal, psychological, and sociological implications. The potency of violence in context on the ethnographic ground, Riches says, stems from how it is used as a means of transforming or otherwise maintaining the social environment by "dramatizing the importance of key social ideas" (Riches 1986: 11), such as gender performance. For example, in Judith Butler's 1990 work, she discusses a transvestite, who, when not engaged in a clearly staged performance, ends up on the receiving end of violence. The key social idea here could be seen to be one of strict gender binaries, but there is another key idea about performance and performativity: that performance is to be clearly marked and bounded as performance in the dramaturgical sense of the word. 
Now let us turn to an examination of gender-based violence as a wider phenomenon, examined in Sally Engle Merry's work. While Riches and other scholars of violence tend to work around gender or avoid its entanglements, Merry offers an anthropological framework specific to gender-based violence.

First, says Merry, an anthropological perspective sees gender-based violence as an issue named by social movements, for example, in terms of naming local practices as a form of gender violence. Labelling sexual assault taking place between acquaintances, as a form of sexual assault is one such example. Further, it examines the interplay between interpersonal violence, power dynamics, and ease of exit in abusive relationships, as linked to those state, community, and social institutions that both define gender and provide the context within which it is performed (Merry 2009: 20).

Merry's framework emphasizes culture and context as opposed to purely psychological or biological dimensions of violence, and focuses on meaning in both interpersonal and structural context (Merry 2009: 19).

My study, given its approach, speaks best to an examination of performances of gender and violence, and towards examining the relationship between interpersonal violence and access to support with which to respond to violence. However, it strikes me that we can view how some of these structures of violence and gender performance work on the ground - through safety-seeking behaviours, through the violent interaction itself, and through measures taken to ensure violence does not happen again.

Randall Collins' 2008 Microsociological Theory of Violence attends to violence as an interactional process. Collins' definition of "successful violence" hinges on an aggressor's ability to appropriate the emotional energy and rhythm of a social interaction 
at the expense of their victim (Collins 2008: 19). Normal interaction builds solidarity because of peoples' tendency to "become entrained in each other's rhythms and emotions during interaction" (Collins 2008: 20); and interaction at cross-purposes generates 'confrontational tension' which becomes fear at higher intensity, preventing most violence (ibid). The instant an aggressor overcomes confrontational tension and does violence to their victim is what Collins terms 'forward-panic':

“...the tension/fear comes out in an emotional rush....It resembles a panic, and indeed the physiological components are similar, [the aggressor] is in an overpowering emotional rhythm, carrying them on to actions that they might not normally carry out in calm, reflective moments"

(Collins 2008: 84)

This situational positioning, argues Collins, creates a victim whose weakness is borne out of the interaction during the struggle to establish situational dominance (Collins 2008: 135), and an aggressor whose bodily responses to the now-weakened victim bring them to do violence, particularly where the victim tries (unsuccessfully) to resist.

I should note that Collins' full argument is not that violence occurs on a spectrum, but rather that most people are 'not good at violence' because they typically do not push past confrontational tension, but rather, find ways to de-escalate conflicts before they can reach a point of physical violence (Collins 2008: 20). Further, Collins argues that among humans in general, there are a 'violent few', who find their calling in organized crime, the military and policing professions, and a 'violent elite' who find their calling as assassins, top soldiers with the highest body counts, and so on (Collins 2008). I do not agree with this premise, however, I can appreciate what Collins has to say about the violent situational process itself, and believe it can fit into a notion of violence that accounts for a spectrum and social context of aggression and violence. 
Collins' point on situational weakness raises an interesting question: what created the weakness in the first place? Collins suggests it is entirely interactional (Collins 2008: 135 ) and that socialization, gender-performance, and social norms do not structure the situation to begin with. Mary Stewart, following Erving Goffman, points out that "in our everyday interactions, we are likely to avoid talking or behaving in such a way as to ruin the interaction; we try to maintain a semblance of normalcy" (Stewart 2002: 173).

Women in particular are socialized 'to not overreact' to aggressive actions and words, and to place greater concern for a relationship or smooth social interaction than their personal safety (ibid). One of the results of this ongoing socialization is that women learn not to trust their own feelings and perceptions, says Stewart, "and so may respond [to violence] more slowly or weakly than would be effective" (ibid). This point is key for self-defence, and I will return to it later on. Sylvia Burrow also points out that socialization of femininity creates a network of behaviours that inculcate and announce women's membership in a "lower caste and [their] unwillingness and/or inability to defend [their] bodily...integrity” (Burrow 2008: 129).

Now let us return to Collins, who writes that the ineffectual resistance of the passive victim seems to make the aggressor disgusted and increasingly angry to the point of continuing the attack, just because of his anger at the victim's cringing (Collins 2008: 150). He writes of this particular moment of violence as if it were one of two patterns of abusive violence found in everyday relationships. It strikes me, however, that it is not. Forward-panic is an affective expression tied to the moment of violence itself, which Collins describes as occurring in a variety of situations: military actions, police violence, bullying, and robbery, to name a few. 
Collins' exploration of abusive dynamics does not make the connection between sudden confrontations and incidents and patterns of abuse, which occur over time. Lenore Walker's 1979 exploration of the cycle of abuse allows us to see such episodes as the battering or acute phase of relationship violence. Collins describes abusive dynamics as a 'terroristic torture regime', which "does not build on sudden confrontations and incidents, but seems much more deeply premeditated by the aggressor....in which he picks on his victim, looking for petty issues and occasions, even starting up without ostensible provocation of any sort" (Collins 2008: 152). This looks very much like the tensionbuilding phase of the cycle of violence, which would precede a battering episode (Walker 1979). Given Collins' emphasis on the exchange of emotional energy as a primary goal of abusers, particularly in that they seek weak victims without the energy to defend themselves effectively from these kinds of exchanges (Collins 2008: 152-153), and that abusers and their victims also learn to be around each other as well (Collins 2008: 153155), it strikes me that Collins also ignores an important aspect of an abusive dynamic: why would a victim stay, if the abuser did not offer a reprieve from the violence, which would ostensibly let them recoup some of their energy? Walker's abuse cycle addresses this with what is termed the 'honeymoon phase' (Walker 1979). Collins treats relationship violence as if it were clearly distinguishable between either a series of sudden occurrences resulting from confrontational tension, or a terror regime characterized mostly by threatening the victim and playing upon their hopes of appeasing the aggressor (Collins 2008: 152). Given how Collins tends to restrict his definition of violence to that which causes physical harm in the examples he uses later in his book, and that the 'terroristic torture regime' only figures into his description of abusive relationship 
violence, then it almost appears that abuse occurring within intimate relationships is not 'real' violence. This is why I have presented it alongside Walker's more complete model.

Also, by attending to the problem of violence from such a situational, interactionist perspective, we lose some of what makes social performances so important: maintaining and/or contesting a given social structure (in this case, gender). With that said, Collins' situational view of violence is important, in the right contexts: namely examining how self-defence training works to help participants interrupt a violent situation and gain control over it (or escape it). Alongside a phenomenological approach which takes our lived world - our milieu - into account, Collins' analysis becomes a powerful one.

For example, it is one thing to train oneself to interrupt impending violence by not-cringing, or by learning to yell 'NO!' at an aggressor: it is another to consider what brought us to self-defence in the first place - on some level, what brings participants to self-defence classes is facilitated by a disconnect between wider public discourse around personal safety, and lived realities of violence, or perceived vulnerability to violence.

Elizabeth Stanko's 1988 work highlights how such contrasts create a climate of un-safety for women, via a dominant public discourse of stranger-danger, as opposed to private realities of gender-based violence (Stanko 1988: 9). For example, Stanko writes, "Safety advice offered... reinforces women's knowledge about vulnerability - to male strangers" (Stanko 1988: 86). Wherever women happen to be, they are taught to 'look out for danger' when they are out in public.

Stanko further writes that,

"wherever women are, their peripheral vision monitors the landscape and those around them for potential danger....on the street, they listen for footsteps and avoid looking men 
in in the eyes....at home, women are more likely than men to ask callers to identify themselves before opening the front door and to search for ways to minimize conflict with potentially violent partners" (Stanko 1988: 85).

Stanko points out that "worry about personal safety is one way women articulate what it means to be female and live, day-in and day-out, in communities where women are targets of sexual violence" (Stanko 1988: 86). By contrast, men tend not to exhibit this worry about safety, and as Stanko points out, "there are no tips about personal safety in crime prevention handbooks....it is assumed that they are able to protect themselves" (1988: 109) despite their recorded levels of victimization - at the hands of other men being much higher than women's. Here is where Collins' (2008) assessment that most people are not very good at violence becomes useful: if men are not as able to protect themselves as they believe, where is the wide public discourse of concern and plethora of private responses for men's personal safety?

Alarms, self-defence courses, advance planning, and better lighting, are only a few of the list of precautions women take against violence, again in response to public discourse about women's safety (Stanko 1988: 149). However, Stanko writes that "such solutions mask and foster the most significant threat to women's safety: those men with whom women are most familiar" (ibid) and further, she says that the very structure of women's lives places them in danger (ibid).

All of this is to say that the world women are responding to when they take selfdefence classes, is a world characterized by vulnerability to violence; however, there are some drawbacks to the approaches I have outlined thus far.

Stanko's work is not without its own difficulty: that is, of being so detailed that it can be difficult to see the patterns that emerge from those details. Put another way, 
Stanko highlights many concrete details of women's experiences with safety/danger, or vulnerability to violence, but on their own, they are something of an assemblage of facts, without a clear way to see how they express something about uses of violence in a culture, or about safety and risk-management, threat, or vulnerability in general.

Stanko's list of all the precautions women are encouraged to take in response to the public discourse of stranger-danger does not exhaust a discussion of how they develop as bodily habits - particularly regarding self-defence - as ongoing responses to vulnerability, real or perceived.

\subsection{Self-Defence and Martial Arts in Response to Vulnerability:}

Because this project had its beginnings in women's participation in self-defence, much of the literature collected on self-defence tends to highlight women. With this said, much of the literature pertaining to martial arts or other combat sports, while including women, tends to either be gender-neutral or to highlight men and development of masculinity. My study is mainly focused on the process of women taking up the practice of self-defence in response to gender-based violence; however there is room for observations on men addressing violence, vulnerability, and aggression in general. With this said, now I will turn my discussion to a feminist sociology of self-defence and anthropology of martial arts. Much of the sociology or anthropology highlighting women's participation in selfdefence, martial arts, and other combat sports tends towards discussions of:

- The 'self-defence benefits of martial arts through building physical capability to respond to violence, and cultivating confidence in the capabilities of one's own body. 
- The benefits of self-defence practice itself and the problems with 'women's safety discourse' without examining the process of learning self-defence.

I will discuss these two approaches with a view to how I will be approaching self-defence practice as a response to vulnerability and violence.

Without giving away too much too soon, I will say that my approach will bring the focus to the dynamics between the learning process, bodily practice, and addressing problematic discourses in self-defence.

\subsubsection{Martial Arts as Self-Defence: Training Perception}

In this section, I will examine both academic and martial artists' reflections on restructuring participants' relationships between themselves, their bodies, their habits, and even certain aspects of the self-other relationship. The academic studies of martial arts tend to use conceptions of the body and its habits developed after Bourdieu and Foucault, at times examining not the body itself but the discourses surrounding it. Because I aim to examine bodily experience itself in relation to wider discourses (without excluding lived bodies), it is less the theoretical perspectives used by the academic authors here that interests me, and more the martial arts training itself being studied by these authors that I wish to focus on.

Einat Bar-On Cohen, with Deleuze and a boundary-less 'body without organs' in mind $(2007,2009)$, focuses on how an intense physical practice can restructure a participant's way of relating to his or her milieu, from the body outward. For example, in her 2007 work on 'perfect timing' in karate, Cohen examines the phenomenon of 'catching the opponent's decision' (Cohen 2007: 8), where a practitioner trains 
extensively through sparring matches to see (usually through peripheral vision) the micro-movements a sparring partner might make just a fraction of a second before they move to attack (Cohen 2007: 7-9). I will return to this sense of 'perfect timing' later on, as it is sometimes trained in self-defence contexts, albeit over weeks instead of years. Martial artists engage in years of intensive sparring and training of the gaze to appear to look into the eyes of an opponent while opening up the peripheral vision in such a way as to 'catch' the small movements, that give a sparring partner's intentions away. In selfdefence, this heightened sense of vision paired with proprioception is also sought after. Cohen also discusses uses of pain as a training tool in karate, namely through kibadachi (horse-rider's stance) meditation, a group training practice in which students take up a stance with the legs held wide from the body, and crouch down, immobile for up to an hour and a half (Cohen 2009) in spite of the pain. Although the context Cohen describes is one of special training, her discussion of pain and its analogy to violence is an interesting one, particularly where I will be discussing how self-defence training does (or does not) use pain as pedagogy (Cohen 2009).

On violence, pain, and defending oneself, Cohen also points out that:

"...violence is the central issue in the world of martial arts. Karateka [students] train for many years in order to learn how to defend themselves against an attack, and in so doing they acquire the skill to divert violence from its course" (Cohen 2009: 619).

I will return to the topic of pain when I discuss phenomenology in this chapter and again later on in the thesis when I attend to pain-training as a way of interrupting one's fear of pain, and thereby the vulnerability associated with that fear.

Jaida Kim Samudra's work on body movement, space, and White Crane silat, an Indonesian martial art, is both an argument for what she terms 'thick participation' and 
reliance on sensory data in ethnographies of physical practices, and an examination of how practitioners learn to trust their bodies through silat (Samudra 2008). Samudra writes that "silat training is supposed to teach students to trust their hearing, vibrations through their feet, and changes in temperature or air pressure on their skin to register other peoples' nearby movements" (Samudra 2008: 673). By maintaining hand-to-hand contact during training, says Samudra, practitioners hone their tactile sensitivity to their own and their partners' "dynamic, rapid adjustments of direction, balance, speed, and force" (ibid). This is called 'feeling' training (ibid) and is a skill common to martial arts, boxing, and even self-defence to some degree: training the senses to be aware of an attacker and their intentions before the attacker can act.

Marc De Grave's 2011 work on proprioceptive 'blindness' training undertaken by Javanese martial artists explores a form of sense-training within pencak silat, or martial arts of the Malayan peoples (De Grave 2011: 126) known as getaran (De Grave 2011: 129), which makes use of 'vibrations' within the body, in order to sensitize practitioners to their own 'vibratory frequencies' and to those of objects and others in the world around them (De Grave 2011: 131-132). Practitioners engage in breathing exercises along with forms of meditation in order to 'quiet' their minds, and to be able to attend directly to their proprioceptive senses (De Grave 2011: 130-33), making them highly receptive to sensory input.

\section{De Grave writes}

“...the practitioner...must close the 'external senses' (smell, hearing, sight, taste), calm their emotions and thoughts, and focus their attention on internal feelings, the relation of interiority with externality - particularly on the skin but also through breathing frictions and proprioception. With the aid of these breathing exchanges and sensations, they increase their internal receptivity and contact with the environment" 
(De Grave 2011: 132).

De Grave writes that "the basic application into which the practitioner is initiated is the detection of obstacles.... and the exercise consists of having to detect the obstacles in order to avoid them" (De Grave 2011: 132). However, De Grave also notes that "the various capacities to which getaran leads should not make us lose sight of the fact that the techniques are supposed to make it possible for practitioners to learn how to know one's inner self, to control one's emotions, one's behaviour, one's relations with others, and one's intimate relationship with the world" (De Grave 2011: 134).

In the work of Cohen, Samudra, and De Grave, we catch a glimpse of the process of learning some techniques common to martial arts - sensory techniques whose premise is 'quieting' the mind in order to act with the body in a particular way, to respond to both the world one lives in, and to manage one's own responses to that world. Common to the three martial arts discussed above is again the notion of habituation, in this case the idea that it takes years of ongoing practice to be able to execute these techniques - particularly the ones based on heightened awareness of one's responses to the world, and awareness to one's surroundings, because they encapsulate forms of self-development (emotional control in getaran training) in addition to bodily awareness.

Martial arts practice as a process of self-development is also discussed in nonacademic publications, highlighting the author's development as a martial artist (Loren 2001, Leung 1992), or the author's process of helping laypeople develop internal selfconfidence alongside the physical confidence gained through self-defence or martial arts practice (Gee 1992).

Janet Gee writes that good self-defence practice includes the cultivation of vision, 
hearing, and intuition (Gee 1992: 78). Properly trained vision does not only see in the ordinary, but does two things, suggests Gee: "a piercing look can be devastating to a would-be assailant if used properly....being able to 'stare down' a potential assailant might help eliminate the threat of becoming a victim" (Gee 1992: 78-79), and in contrast with focused, piercing vision is "the ability to take in an area through peripheral vision, helping a woman avoid a potentially dangerous situation" (Gee 1992: 78) by being more visually aware of her surroundings. Hearing properly, says Gee, gives a woman another self-defence weapon - focused, directional hearing (Gee 1992: 79). Intuition, suggests Gee, is the most difficult of the three to train, although the way she describes teaching her students to "observe one another and try to describe such things as the person's ways of carrying stress in the body (tightening shoulders, clenching the jaw, etc.)" (Gee 1992: 80), it seems to be a deep integration of sight and hearing, plus 'gut feeling'.

BK Loren's biography, The Way of The River, challenges assumptions about who 'needs' martial arts or self-defence. Three of her vignettes concerning self-defence and martial arts classes show her teaching an ethnically diverse, working-class group of women in the inner-city, a group of mostly white women in a rural, agriculturallycentered community, and a somewhat ethnically diverse group of middle-class suburban housewives (Loren 2001: 133-154). Packed into the vignettes is a critique of middle-class assumptions about inner-city danger and suburban 'safety' (2001:153), and she points to how 'safety' discourses play out in the lessons taught and learned among the three groups.

Debbie Leung, a martial artist since 1978, writes of her practice as beginning first out of curiosity, and then out of a growing desire both to show women practical responses to the violence they face (Leung 1992: 66), and to offer her students "a broader 
perspective of the possibilities of what women can do, not just physically but also in other realms" (Leung 1992: 67) through martial arts practice.

Self-defence practice, writes Leung, allows for the development of such skills as "identifying an assault [situation] before it escalates...avoiding potentially threatening encounters, being verbally assertive, and using other non-fighting options to escape assault" (Leung 1992: 72). A good self-defence program, particularly women's selfdefence, includes "accurate information about violence against women to destroy the many myths...about it, and examples of the many instances of success women have had in defusing and escaping assault" (ibid), two issues not addressed directly in martial arts, but in the realm of self-defence.

Here in the non-academic literature we can see some of the approach I aim to take in this study, where cultivation of the senses, along with cultivation of emotive or affective capabilities comes together with learning about what one's vulnerabilities are in regards to potential or ongoing violence.

\subsubsection{The Benefit and Problem of Self-Defence Itself}

Now let us turn to the second approach taken towards studies of self-defence, which tends to examine the relationship between self-defence practice and discourse on a very broad level. The scholarship comes closer to the dialectic between the wider social context of women's experiences of violence and of the changes that follow self-defence training, but unlike the non-academic literature pertaining to martial arts, tends to avoid examining the on-the-mats learning process in depth.

This study attempts to fill the gap identified in the second approach by addressing 
what the benefits of self-defence are, based on how self-defence is actually learned or taken up into participants' body-space through practice, and how this relates to the problems of 'women's safety discourse' or even feminist inquiry into self-defence.

How, then, does self-defence training change women's perceptions of vulnerability, and responses to threats or violence, given the previous discussion? In a 2004 journal article, Jocelyn Hollander called for feminist scholars to find out whether self-defence training changes the way women react to actual assault attempts, and whether those changes would be equally effective in more ambiguous situations, such as relationship violence and harassment (Hollander 2004: 321).

In their collaborative study, Amy Angleman, Yoshihiko Shinzato, Vincent B. Van Hasselt, and Stephen A. Russo (Angleman et al 2009) offer an important caveat to selfdefence training, particularly insofar as it tends to take place over a short period of time. Yoshihiko Shinzato argues that self-defence practice cannot offer the same benefits as traditional martial arts training, because practitioners have not had the opportunity to devote years of ongoing practice for several hours a day to take the different techniques up into their body's habits (Angleman et al 2009: 91). Perhaps because it addresses a practitioner's specific concerns of the self/body/other relationship (usually concerns over interpersonal violence), the project of self-defence is one that needs to be taken up as if it were a martial art, by practicing often and taking 'refresher' courses.

Patricia McDaniel's work examines the benefits of self-defence practice in preventing sexual assault through a survey of forty-nine women who completed a fourweek self-defence course (McDaniel 1993: 41-42). McDaniel asked her research participants to report their levels of fear associated with eight specific crimes, including 
rape (ibid). At the conclusion of the self-defence course, the women reported overall that their fear levels went down, most significantly in regards to rape, but also where other crimes were concerned: robbery, threatening with weapons, and battery (1993: 44).

Leanne Brecklin and Sarah Ullman's studies mention embodiment specifically, but are actually survey samples of psycho-social benefits of self-defence training for assertiveness (Brecklin \& Ullman 2004, 2005; Brecklin 2008) in response to a criminological problem on university and college campuses (Hollander 2004). Brecklin and Ullman's work specifically addresses the viability of self-defence for survivors of sexual assault for both primary and secondary rape prevention, as well as self-defence as a form of therapy for rape survivors (Brecklin \& Ullman 2004: 154-156, 2005: 755-757), but they do not discuss, for example, whether survivors had a change of perceptions of vulnerability, or a change of approach to dealing with aggressors in their work.

Those studies that ground themselves in concrete examples of women's narratives about self-defence tend to problematize it in terms of how it may be taught to women: for example, Jill Cermele argues that while feminist self-defence is about empowering women to understand and manage risk, traditional self-defence continues to emphasize traditional gender socialization - crying for help, running away, and pleading with an aggressor, rather than responding with assertiveness or violence towards disabling an attacker (Cermele 2004). Rachel Hall discusses self-defence taking place under notions of 'women's safety' as both potentially empowering and potentially training women towards a form of panopticism towards their environment, their conduct, their ability to not attract attention - in short, again, to do femininity in a way that curtails public movement, that diminishes women's presence in the world (Hall 2004: 6). 
Martha McCaughey's ethnography of women practising various forms of selfdefence and martial arts distinguishes between discourses of women's safety and selfdefence courses, suggesting that while women's safety initiatives may typically be conservative in nature - encouraging restriction of female movement in public space, for example - they are not a form of self-defence, which she defines as female aggression in response to the threat of violence (McCaughey 1997, 1998).

McCaughey writes towards an analysis of self-defence as subversion of gender norms, and that framework continues to serve more recent writers. Kristine de Welde discusses self-defence as a practise which allows women to break with what she describes as traditional narratives of female disempowerment, and to formulate new narratives, of female capability, agency, and responsibility (De Welde 2003: 248), however, again this 'traditional' versus 'subversive' dichotomy is still premised on an unmarked 'default' self-defence participant: white, middle-class, and educated.

Sylvia Burrow's exploration of self-defence training aims to show how the development of self-defence skills "function as a means of overcoming bodily encoded limits to autonomy" (Burrow 2008: 127) by cultivating self-confidence, expressed through the ability to get angry or act defiantly to protect oneself, and one's autonomy with it (Burrow 2008: 130). Women tend to live in social milieus that work to undermine their self-trust, self-esteem, and confidence, whether through threats from aggressors, or through their own socialization. Burrow points out that traditional Western ideals of femininity involve the expectation that women take up as little physical space as possible - elbows tucked in, knees crossed (Burrow 2008: 129). Self-defence practice offers women the potential to interrupt this socialization, but its more immediate aims are to 
prevent physical or sexual harm to the self (Burrow 2008: 131). Burrow's literaturereview echoes McCaughey's ethnography in its philosophy, but by engaging these on the ethnographic ground, my study will show the possibilities and limitations of self-defence as actively taken up practice.

\subsection{The Body in Motion: Phenomenological Anthropology}

The works I reviewed earlier, pertaining to martial arts, tend to focus on the body at a level that does not necessarily respond to practitioners' specific concerns, and the works on self-defence tend to be very focused again on details pertinent to everyday contexts of participants' lives without seeing necessarily the connections between those everyday details and interactional techniques, or between public discourses of safety, danger, or vulnerability, and the responses people take up within their everyday, lived world.

There are a few anthropological works that address some of these connections with regards to martial arts and other combat sports, through phenomenological frameworks. Dale Spencer's 2012 Ultimate Fighting and Embodiment, examines mixed martial arts as a mode of performing masculinity through both aggression and physical endurance of pain, as well as violence as a situational process (Spencer 2012). Spencer's work also looks at the learning process behind taking up mixed martial arts. His analysis of the body and its responses to others as well as its own immediate situation inspired my own analysis, which we will see in chapter five when I discuss how the body learns in a self-defence context. Loïc Wacquant's work, Body and Soul (2004), takes up Bourdieu's notions of field, habitus, and bodily capital to discuss how boxers cultivate both physical capability and aggression in the boxing ring as they mitigate their own responses to 
aggression outside the gym entirely. Boxers tend not to want to get in fights outside the gym, says Wacquant, as it may hurt the careers they are trying to build as a means of escaping their neighbourhood or escaping day labouring jobs (Wacquant 1995, 1998). Though I do not engage Wacquant directly, aggression-management did come up in the course of fieldwork.

It is at this point that I want to turn to phenomenology proper and discuss what phenomenology offers in general, and follow that with a discussion of what phenomenological approaches have to offer a study in how self-defence changes participants' everyday experiences of vulnerability to violence. First, however, let us bring this method of doing philosophy together with anthropology. For this, I look to Tom Csordas, whose cultural phenomenology aims to strengthen anthropological explanations of lived experience through such notions as somatic modes of attention (Csordas 1993: 147) and through a clear definition of embodiment, its relation to experience, and how we can understand that experience. Drawing on Barthes' notion of text and textuality, Thomas Csordas argues for an understanding of the body as biological entity on one hand, and embodiment as methodological field defined by perceptual experience and mode of presence and engagement in the world on the other (1993: 135). Embodied experience, says Csordas, should be understood as the starting point for analyzing human participation in a cultural world (ibid), and his argument lines up with my own about understanding self-defence participants: before we can ask whether changes occur following training, or how effective they are towards thwarting an attack or dealing with micro-aggressions such as harassment or relationship violence, we need 
to concern ourselves with how changes occur during training at the embodied level of a certain natural attitude or being-in-the-world.

Michael Jackson might be inclined to agree with such a sentiment, given his assertion in his 1989 volume Paths toward a Clearing that being creatures of habit, we are our habits, and these cannot be changed at will: "to change a body of habits, physical or cultural, can never be a matter of wishful thinking and trying; it depends on learning and practicing new techniques" (Jackson 1989: 119). People taking up self-defence, or a long-term study of martial arts, are seeking to become different at the level of the habituated body: able to apprehend the potential risks of the world and on a level that does not recapitulate the fear or trauma that may have brought them to learn self-defence or martial arts in the first place.

In his 1999 essay on the body's career in anthropology, Csordas argues for an anthropology of bodies in motion (Csordas 1999: 190), suggesting that while bodies in their spatial orientation have been covered at length, more attention was needed to what people actually did with their bodies in that space. At the time of writing, Csordas noted that "....the only concerted elaboration of this analytic angle is in the relatively small field of the anthropology of dance, which is concerned with dance in ritual and non-ritual settings, and more broadly with the cultural patterning of movement" (ibid). Since Csordas' essay, anthropological inquiries into martial arts and combat sports have offered a growing contribution to an anthropology of bodies in motion, of embodied knowledge, and of gender and the body. It is on this note which I want to expand particularly on embodied knowledge, through phenomenology. 


\subsection{Self-Defence from a Phenomenological Point of View}

Before I expand on phenomenological inquiries into martial arts or other combat sports, I will first discuss phenomenology more generally. To paraphrase a definition based on Merleau-Ponty and Husserl, phenomenology is the philosophical exploration and discourse about that which appears through lived human experience, that is, the experiential process of a given 'something', be it a sound, a touch, a smell - or a unity of experiences, such as a performance, a verbal conflict, or taking up a practice (such as self-defence). To address the nebulousness of human experience through a phenomenological lens, we first begin with the scholar's experience of the thing itself (Merleau-Ponty 2012: 1xxi). Though the scholar might have his or her own assumptions about the thing, these are bracketed aside in what is called the phenomenological epoché, or reduction to the thing itself, beneath the layers of meaning usually given to it in everyday life (Merleau-Ponty 2012: 1xxiv-lxxv). What remains after this bracketing, are the phenomena which we set out to describe and explain: things that appear as something in consciousness.

Phenomenological investigation, then, is less concerned with the content of a given experience, than it is with how an experience presents itself in consciousness. In everyday life, what is being examined is that 'space' itself where experiential reality emerges from the encounter between body and world; self and other. The problem with such an approach lies in its broad range - given that an experience can range from being something as narrow as hearing a sound, or as wide as taking up a skill-set, the use of phenomenological techniques or concepts in ethnographically grounded explorations tends to make use of some delimitations of the phenomena being studied. 
For the purposes of this study, what is being examined is how self-defence training, for all the physical and verbal techniques learned, changes practitioners' perceptions of, and relationship to, their vulnerability to violence.

Phenomenology allows us to see the process behind developing a habit, or taking up a skill - self-defence, in the case of this study, and see both the possibilities and limitations of taking up the practice; from the new modes of surroundings-awareness learned in classes, to the discussions of where danger is more or less likely to present itself. Participants learn to use their bodies in new ways to communicate with the world at large, starting with using their senses in a particular way, and working their way out to training immediate, effective responses in threatening situations.

Merleau-Ponty's Phenomenology of Perception forms the foundation of my understanding the processes behind violence, and behind the responses people learn to address it in its immediacy. Consider the case of communication, which Merleau-Ponty describes as "achieved through the reciprocity between my intentions and the other person's gestures" (Merleau-Ponty 2012: 190) and vice versa, such that communicative gestures indicate specific, sensible points in the world and invite a response (ibid). Recall Collins' assertions of how a violent incident escalates, where one (situationally-weak) party ineffectively resists the aggressor, which Collins says, brings about an overkill response of violence (Collins 2008: 19-20, 135, 150). Both Merleau-Ponty and Collins would seem to be in agreement here - that one's communicative gestures call out particular responses from the Other, on a level that may seem involuntary (such as responding with physical aversion to the sight and sound of an assault). 
Merleau-Ponty's concept of the milieu and its dialectics with our emotional capacities offer a potential explanation here: "our natural attitude is not to experience our own feelings...but rather to live according to the emotional categories of our milieu" (Merleau-Ponty 2012: 399), that is, the world in which we are socialized, educated, and in which we work, live, and relate to others. This is important: If, as Sylvia Burrows suggests, the ideal of femininity continues to be based on "a network of behaviours through which we announce to others our unwillingness and/or inability to defend our bodily or moral integrity" (Burrows 2008: 129), then here is a taking-up of a category of responses to boundary-violations, most of them not involving anger, but either nonresponse, or attempts to appease the aggressor - and such behaviours are rooted in a wider cultural milieu. Focusing only on the immediate interaction tends to lose this perspective - even though in phenomenologically informed inquiry, we might bracket this aside and ask what it is, in this given interaction, we are seeing. We do this to understand the processes behind the interaction, but as anthropologists or sociologists who are not entirely engaged in phenomenology alone, we still consider how the wider milieu (lived world) influenced that interaction, that communicative gesture, or that behaviour.

A phenomenological lens, in spite of this bracketing and placing-back into context, still allows us to see the process behind how habits build and sediment over time into our body schema, that is, how people take up a given set of behaviours or communicative strategies to the point that they no longer need consciously to call them up in daily life. For the purposes of this study, a phenomenological lens also allows a view into some of the limitations of self-defence training as a response to personal violence beyond its situational character. In particular, phenomenology allows us to see 
how much time is needed to change the total body/self and its habits, such that a selfdefence participant could change how they relate and respond to violence and vulnerability.

Phenomenology also allows us to see the types of tropes being challenged in a self-defence context at an embodied level. For example, Straus, in Phenomenological Psychology, suggests that our standing upward against gravity leads us to inscribe values into space around us, values associated with height and level, being above or below, tall or short (Straus1966: 142). Considering the phrase "to stand something", Straus suggests that with/standing is "characterized as resisting and therefore enduring against threat, danger, and attack" (Straus 1966: 143). Here is a potential counterpoint to Straus, because while he discusses standing as endurance against threat in a somewhat metaphoric sense, it offers some insight into postures learned by participants in a self-defence program. On the one hand, enduring against real threat, danger, and attack is actually often best done by surprise, trickery, and deception. On the other, a self-defence program which incorporates assertiveness training would probably make use of Straus's suggestion that 'to stand' is very much to take up space, and to assert this through the body as well as through use of voice tone, language, and gesture - all in ways which associate well with 'uprightness'. At the same time, recalling Collins' assertions about how gesture, as inflected by posture, call forth a violent response in an aggressor, we can see how use of posture in self-defence allows for the kind of deception required to bring an aggressor's intention to the surface and respond to it. We will see this emphasized in future chapters when I discuss particular modes of self-presentation, awareness, and communication as learned through both the women's and advanced self-defence classes. 
I would go even further along a discussion of challenging tropes (particularly as they are embodied) with Michael Jackson's ideas and say that one of the means by which self-defence and martial arts practitioners habituate their bodies in new ways is through metaphor. Jackson writes that "metaphors coalesce social, personal, and natural aspects of Being, as well as unifying ideas and practices... it is to be expected that metaphors should often be called upon in resolving double-binds and in making people whole again" (Jackson 1983: 138). This comes up often in more 'story-oriented' self-defence classes such as the women's class I worked with, where interactional tools and ways of codifying one's feelings and responses to potential threats served as a metaphor for objectivity. For example, by presenting one's feelings about a situation along a colour-coded spectrum and presenting the behaviours of aggressors as triggering those feelings, those taking the classes could show that their feelings, responses, and 'intuition' were, in fact, objective responses to threats, as opposed to other, more dominant narratives used about women's responses to threats (that they are 'overreacting'). Further, Jackson says that "by facilitating movement within the total field of Being, metaphor is a crucial means of locating areas where we can act upon those areas where we have lost the power to act" (Jackson 1983: 139). In self-defence training, particularly in the women's class, a hypothetical aggressor typically coded as 'male' served as the zone in which we could act, and train ourselves to act appropriately along a spectrum from 'normal', polite interactions, to responding effectively and without apology to aggressors. However, Jackson also cautions that "when metaphor becomes an end in itself and loses its instrumental value as a means of moving us among various domains of Being and integrating them, a person gets stuck on the metaphorical vehicle..." (Jackson 1983: 
140). This strikes me as one of the limits of self-defence as an embodied metaphor for regaining control over one's boundaries, and one's Self: some of us (this happened to me in particular) can get lost in just learning technique after technique, to the point that we become 'stuck', unable to progress beyond an assemblage of learned techniques which, by themselves, cannot move us towards healing - even if 'healing' simply means responding more effectively to threats. It is in the incorporation of these techniques, in the synthesis of these techniques into other aspects of Being - say, of learning how to say 'no' effectively, but then also learning when and how to say 'yes', or learning how to back up 'no' with either physical force or strategy if that 'no' is being ignored.

I want to turn to a brief discussion of training and its problematics here. In the context of a self-defence class, practitioners are aiming to change the way they relate to the world, to self and other, and how they respond to situations in daily life that present risk or increase vulnerability to violence. The problem with this is found in the length of time spent in a self-defence class. The two classes I participated in were upwards of eight weeks, but I want to highlight again - the level of bodily habit being 'targeted' through such training is one which takes years to re-train. One of the questions being asked in this study has to do with the effectiveness of changing how participants both perceive and respond to situations of risk in a general way. Straus writes that a physical practice involving learning movements will tend to follow an

"inner systematics involving a gradual differentiation of movements and sensory data, the formation of constants, the focused organization of individual movements within this region, which in turn furthers a differentiation of movements and assimilative grasp of their extent" (1963: 256).

A successful student in this case learns the patterns of movement, not individual movements in themselves, and by taking up these patterns, they learn a new mode of 
movement "within a field whose dimensions are smaller than those of everyday movement" (Straus 1963: 257), i.e. whose pragmatic uses are specific to a narrow range of situations. In a self-defence context, participants learn to use some everyday movements and everyday language in a particular way - to protect themselves in particular situations, and for some participants, to open the doors to a new range of habits and perceptions surrounding safety, threat, and danger, entirely. Such habits, and uses of the body take a great deal of time spent repeating the component movements that make up a technique, then repeating the technique in a variety of role-played situations. The aim of such practice is to facilitate that technique settling into the habits and behaviours that make up one's body-schema, or pattern of habits and techniques that can be calledupon spontaneously in social interaction. Following Merleau-Ponty, body-schema is "the global awareness of my posture in the inter-sensory world" (Merleau-Ponty 2012: 102), but only insofar as the body exists towards its goals and tasks (Merleau-Ponty 2012: $103)$.

Self-defence practice, for the repertoire of new body-movements, verbalizations, and techniques, aims to change not just a collection of habits, but the body-schema under these habits - the very way in which practitioners are aware of themselves in their surroundings, aware of and with their bodies.

For example, as one trains the entire body into both capability for self-defence and exuding a sense of that capability, one uses the body in all its capacity to move and take up space in new ways.

The entire person trains both to use their body in situations which might require self-defence, and into a more generalized upright posture (unless using posture to trick an 
attacker) which, following Straus, suggests endurance and therefore can be culturally understood as a kind of confidence. These more generalized notions of trickery, deception, and confidence are located in the body-schema: not at the level of a specific technique, but at the level of a generalized sense of being able to defend oneself, should a situation call for it, and of having the sense of self-worth that would encourage a practitioner to defend themselves in the first place.

Such confidence in itself becomes more than a potential defence strategy, in that it involves setting and maintaining boundaries at a generalized level which can be turned towards specific ends without conscious effort. Consider physical pain and its threat to one's boundaries: pain itself, according to Drew Leder, threatens to unmake the world by rendering the body in pain as the only focus of our attention (Leder 1990: 18-19).

Confidence and embodied understanding of how one's boundaries are worth defending might be quickly turned to the immediacy of an escalated situation in which an attacker has used pain as a way of breaching boundaries and taking control of a situation: this brings us to a structure of confidence and 'withstanding' not usually directly addressed in discussions of self-defence - the ability to take pain and respond to an attack in spite of it. Adrenaline can do this on its own, but in the context of self-defence training, participants learn to work with adrenaline and channel their responses in a particular way - very little time is given to be in pain, or let pain 'unmake the world' (Leder 1990). Again, this ability to respond to such situations decisively, it seems, comes from the entire body-schema; that understanding of the body, its spatiality, and its sensations, which comes about through the development of habits aiming to change the person at this generalized level. 
Self-defence, then, for the repertoire of bodily habits, presents a practitioner with a wider range of potential responses towards the threat of the world from 'out there', that otherwise are not pre-given, either from the training or from previous stocks of responses one might have had to the Other. Discussing creativity and contingency in responses to the demands of the Other, Bernhard Waldenfels writes that "what is at stake here can be put quite well in phenomenological terms: something appears as something, as somebody, but in such a way that it appears in this way rather than in another" (Waldenfels 2007: 13). Self-defence gives the person the opportunity to apprehend the world in such a way that it is not threatening anymore, though it may be a place to treat with respect; to interact with others along these lines as well - where before training they may have appeared threatening, now, they need not appear so - and it strikes me that again, this is a phenomenon of the body-schema, where, rather than a specific habit of awareness or perception of situations, we are seeing a generalized response, that is, until a specific threat appears.

Through this study, I am aiming to give a phenomenological exploration of how self-defence changes one's experiences of vulnerability (which I would define as lived threat of violence); habits associated with attending to these, and changes to one's way of relating to his or her own bodily responses to others, but for a moment let us recall that phenomenology requires a bracketing-out of those everyday significations which overlay a given experience. For anthropology, this presents a problem: we are social creatures, we make meaning, and to a degree, there is a certain meaning being made in the project of attempting to bracket out such things. Thus, this project makes some use of the phenomenological method, but in doing anthropology, keeps social context in mind. 


\subsubsection{Learning Through the Body as Process and Problem}

I want to guide the reader towards an understanding of self-defence training on the ground; in its confusing, and sometimes painful moments through the learning process itself, starting with a little extrapolation of how the body learns.

The classes I took were both billed as being self-defence one could learn quickly, and while this is true with regards to individual techniques, taking up a willingness to defend oneself takes longer, and involves practice outside the training hall in a way that goes beyond a commonplace idea of 'practice by repetition'. The instinct to protect oneself can be built up over time, such that it 'sinks into' the entire person; from their immediate bodily responses to aggression, to the words they choose in that situation.

The willingness, however, stems from a set of relationships extending from oneself to others - it is not so different from learning to love oneself; as being willing to defend oneself is premised in the notion that what one has is itself worth defending. It strikes me that one can train something like a self-preservation reflex where physical techniques are concerned (for example, training a person to endure the physical pain of defending oneself from attack to avoid more serious injury); but training the 'willingness to defend oneself' in a more general way requires a different strategy, and one not based on 'conditioning the reflexes' as is often done in self-defence, martial arts, and other combat sports. This chapter, then, will focus on two aspects of self-defence - the emotional-affective capabilities associated with being willing to protect oneself, and the physical capabilities commonsensically associated with self-defence. 
The process of changing habits with a mainly physical component, such as jabbing at the throat of an attacker holding one's neck in a chokehold - is relatively easy to train through the repetition of individual techniques. Those techniques, when incorporated fully into the body-space can become something like conditioned reflexes, albeit appropriate to a specific situation. Merleau-Ponty writes that "reflexes themselves are never blind processes: they adjust to the 'sense' of the situation" (Merleau-Ponty 2012: 81), and this resonates with Gavin de Becker's discussion of the fear response, which, when allowed to express itself during times of physical danger, can actually manifest as calm, as opposed to the panic which, as suggested by Collins (2008), can lead to further violence. Thus, training specific responses to fit the 'sense' of a situation responding to a chokehold by striking a soft point on the body that one can reach, for instance (the eyes, the centre of the throat just above the sternum).

Further to changing habits, however, Merleau-Ponty writes that "acquiring a habit as the reworking and renewal of the body schema presents significant difficulties for classical philosophies, which are always inclined to conceive of synthesis as intellectual synthesis" (Merleau-Ponty 2012: 143), and self-defence training in a western context tends to continue to treat learning via repetition in this very cognitivist way. But MerleauPonty further says that "every mechanistic theory runs into the fact that the learning process is systematic: the subject does not weld individual movements to individual stimuli, but rather acquires the power of responding with a certain type of solution to a certain form of situation" (ibid) and this is the problem with attempting to use rote learning as a pedagogical technique especially over a relatively short period of time, 
particularly where more than just one's ability to execute a given physical technique is at stake.

Changing more general affective-emotive capabilities requires a synthesizing learning process, however - and even self-defence techniques based on using the body to respond to physical aggression go through a more complex process than repeating a given technique over and over. Let us consider the process of learning a skill in general through Straus's 1963 work on learning and reflex-conditioning for a moment.

Erwin Straus writes that no matter how frequent, repetition alone does not allow us to co-ordinate the tactile and kinesthetic with the optical senses in such a way as to facilitate taking up a discipline (Straus1963: 225), particularly such a physical one as a combat sport, or one with such pragmatic aims as self-defence. A practitioner's ability to put combined techniques or skills in such a way as to effectively respond to a given situation is not borne from repetition alone, even if from years of practice or exposure to the skills in a setting that allows for the practitioner to try new combinations of the component-skills they learned previously. Straus discusses repetition in an experimental setting, but it strikes me that repetition is used in learning in a similar fashion - repeating component movements, to create a full technique, which then becomes useful within a given set of scenarios, be they pieces of music, written work, or sparring sessions. All of these repetitions, however, even allowing for variations in sparring sessions, or affective calls pulled up in those contexts, still tend to only allow those given movements and onesteps to 'sink in', or rather, be taken up into that pattern of movements and attitudes making up the body-schema. The technique might 'sink in', but the participant might not have the physical conditioning to call up the technique and use it, or, conversely, it might 
well be 'reflexively learned' but the person using it might apply it in the wrong circumstances - 'going for the eyes' is not always the best option. What I am aiming at is spontaneity and synthesis of technique. Merleau-Ponty writes,

"Acquiring a habit as the reworking and renewal of the body schema presents significant difficulties ...every mechanistic theory runs into the fact that the learning process is systematic: the subject does not weld individual movements to individual stimuli, but rather acquires the power of responding with a certain type of solution to a certain form of situation" (Merleau-Ponty 2012: 143).

Here is a fundamental difficulty of self-defence as a project - one may be able to learn the component parts of a technique, or type thereof, but in the time of a self-defence class, where is the opportunity for both extensive repetition of the components of a technique, and then the synthesis into a full technique, a variation, a skill-set?

The problem is, repetition tends to work for learning 'component moves' that make up a technique: say, learning to grip the right portion of the fingers in order to manipulate the joint at the knuckles; but even then, not perfectly, because not every training partner will respond in the anticipated manner (gasping, wincing). Repetition on its own cannot replace the messy process of synthesizing component movements into a technique, into a series of movements, or into the ability to synthesize these spontaneously into an effective tactic or strategy for self-defence. At the same time, attempting to incorporate highly specific body techniques (an eye-jab, a joint-lock) into the body-schema in such a way that they can be called up spontaneously, does not necessarily solve the problem of being 'ready/willing to defend oneself'. How many situations would call for such specific techniques, if Randall Collins' suggestion that most people are not particularly violent, and even shy away from violence (Collins 2008: 18-20), is to be believed? I should note that both of the self-defence classes I took did not 
rely entirely upon repetition of specific techniques alone: we worked on situational roleplay, albeit repeating similar scenarios from week to week, and building upon those scenarios to speak to wider social phenomena that enabled them (as in the women's class), or to build on the physical techniques we had learned in the previous week (as in the advanced class).

The goal of self-defence training is an ambitious one: to change a participant's perception of vulnerability to violence and to change their responses to potentially threatening situations. Martial arts practice has similar goals - to change perception, responses, and reaction-time in the context of, say, a sparring match; and to change how participants address other problems, for example physical or emotional inflexibility. For these 'life' problems, martial arts tends not to use methods directly related to a practitioner's everyday goals, which may be why martial arts is meant to be a life-long practice; because habituation into a new way of relating to the milieu in which a practitioner lives takes years, not months.

Self-defence training, by contrast, takes place typically over a period of hours, days, or weeks, and when it takes place over weeks, it is one hour of one day per week for some number of weeks, with some at-home practice meant to take place between classes (usually some repetition of given techniques - including the 'awareness-level' exercises discussed in chapter three). Much of self-defence is wrapped up in the practice of such combat sports as martial arts or boxing, where self-defence training may be either advertised by martial arts studios as an additional class or discipline - or where 'selfdefence' capability is presented simply as a benefit of the combat sports practiced at that 
studio. With this in mind, let us now turn to how the body learns techniques and begins to develop habits within a self-defence context.

\section{Chapter: Perceptions of Vulnerability and Violence}

\subsection{Who Takes Self-Defence?}

Before I expand on fieldwork itself, I want to discuss one of the first issues that came up in both the self-defence classes and the handouts and book that we were given in each class. In the women's class, I found that the language of self-defence and of women's safety tends to address a very narrow group of women. This is due in part to the cost of classes unless there is a special event or reduced price, and in part to some of the advice given in these classes, which may not always be safe for a given woman to carry out. The women as portrayed in the 'safety' discourse used in these classes are typically: white, middle class, well-educated, and have access to self-defence and assertiveness training, counselling, legal services, law enforcement, and a social network. When women appear who do not fit this 'default' either in the class setting or in a story used for teaching, that is, poorer women, queer women, women of colour - they are presented as token examples of how a given technique 'works for everybody', without addressing the question of how to bring self-defence into such people's lives. The head instructor of the women's class often shared stories about women of colour effectively defending themselves from violence following the confidence-building exercises of the course. I struggled with whether to include these accounts, before deciding it best to leave them aside: while the women in question might have consented to their stories being shared in that class, they were not present for my study and could not consent to my using their 
stories in detail.

Where taking up self-defence as a whole is concerned, the disconnect between discourses of vulnerability to violence, or 'personal/women's safety', creates problems for would-be participants, particularly if they are people of colour, who may face violent reprisal for defending themselves, first from their attackers, and potentially from law enforcement; or if they live on a limited income, and do not have access to classes; or if they have disabilities, and find the techniques difficult to perform.

Despite both the classes I took being comprised of white, middle-class participants, one of the participants in the women's class highlighted issues of poverty and disability often while she was with us. While she participated in the course only for three weeks, and it would be "easier" to write as though she had not been there, I will not do so. The presence of low-income participants with disabilities matters - because their experiences with vulnerability, threat, risk, and safety directly address the gaps in public (and scholarly) discourses, and because they are often glossed over in these discourses, or treated as 'exceptions that prove the rule'.

Most of the participants in this study otherwise fit the 'default' conception of a self-defence participant, even in the gender-mixed advanced class: mostly white, middleclass, educated professionals with access to a wide range of resources unavailable to someone living on a low income, or living with disability. For many participants, what we learned was 'common sense' to the point of not being obvious as self-defence technique - handing over our things to a robber, for example; or complying with an attacker until the first opportunity to strike and get to safety. It should be noted, however, that such applications of 'common sense' only make sense for a participant with the 
income to absorb the loss incurred by a robbery. In the women's class, Sensei Tasha gave the example of homeless people who had been murdered for not handing their things - in one case a pair of shoes - to a robber, emphasizing that 'you can always get more stuff'.

However, in the case of a low-income, elderly class participant with disabilities, a robbery might as well be a deadly attack, if the robber were to take medication from her. For her, the choice to 'comply-until' she could get to safety would be a more difficult, costly one than for somebody who could run, or who had a steady income, or whose illnesses did not require ongoing medical intervention. With this said, for those who could apply 'common sense' in this new way, self-defence practice offers participants some ways to change how they relate to the world at large, even though they may find themselves tempering their new knowledge to their abilities, or social positioning.

Participants who take up self-defence learn new 'common-sensical' ways of being: of making eye contact, of changing their sitting and standing postures, and of using their voices both as raw power and for verbal self-defence. Participants open the door to learning a different attitude towards themselves and the world, however focused on specific types of situations that may be. This comes out in such training focusing on how to look confident, or how to not act or look like potential victims - in short, focusing on mitigating vulnerability and its appearances.

The aim of self-defence training is to interrupt the ongoing dialectic between vulnerability and violence in participants' lives, first by naming and framing the risks that create or increase vulnerability in 'the world out there', and second by cultivating skills to get to a place of safety in the immediate situation, and, eventually, to decrease vulnerability overall. This ability to understand and approach these risks, coupled with 
the skills learned to address them, can open the door to some new possibilities - a sense of self-worth fundamental to both the development of boundaries and both the skills and the willingness to enforce them, for example.

\subsubsection{Into the Field of Self-Defence}

Both the women's course I took over the summer and the advanced course I took over the fall approached the dynamic of vulnerability and violence differently: the women's course focused a great deal on interrupting socialized forms of vulnerability and developing the willingness to defend oneself. The course also focused on gender-based violence as a social problem bound up with wider discourses of women's safety, some of which actually decreased 'safety' on the ground for these women - thus the course aimed to provide some alternative discourse, as well as physical techniques for defending oneself from interpersonal violence.

By contrast, the course based on Defendo, a fighting style created by Canadian World War II veteran Bill Underwood ${ }^{1}$, focused more on physical techniques and on the dynamics of potential violence in the security and policing professions. For the repertoire of physical techniques - grips, pressure-points, joint manipulations, and throws or controls, the real focus seemed to be more about managing and appearing to manage aggression; particularly where the need to talk to law enforcement or a judge might arise. The vulnerability and violence dynamic was addressed in this context based on the presumed ability of class participants to do damage to an attacker. Whether participants were able to execute a given technique or not when the need arose, the structure of the

1 http://www.fighttimes.com/magazine/magazine.asp article $=330$ 
class gradually created scenarios at increasing stress levels so as to simulate the kind of bodily situation and responses that would come up during a physical attack.

Both courses aimed to effect discernible changes to how participants related both to themselves and others, through training particular modes of communication, eye contact, use of gesture and language; as well as through being aware of one's bodily responses to others and the situations that arise in everyday life, rather than dismissing those responses and potentially increasing one's risk. Both courses also operated on some shared notions of violence in terms of challenging the 'unintelligibility of violence', which I will address later on in this chapter, and on an implicit notion of the 'inevitability of violence', which was harder to address directly. Both courses also attended to developing and defending different aspects of the Self: In women's class, this was the embodied self in everyday life despite the course's emphasis on discourse and discussion. In the advanced class, this was the socio-legal, or professional self, despite the course's emphasis on physical practice, likely due to its adaptation from military and police training. These aspects of the Self are treated together throughout the paper, via the 'vehicle' of the two courses, and with that in mind, let me address some of the difficulties of this and whether I would make such a choice to treat the material this way again.

When I began fieldwork, treating the courses together seemed a natural progression, given that both are run by the same local dojo (training hall), they share some of their content, and philosophical underpinnings regarding violence, and they represent a shared 'lineage' of master/apprenticeship, which continues to be a strong theme in martial arts studios. Knowing who taught whom is one way for martial artists or self-defence practitioners to speak to fighting style, or to verify the 'authenticity' of what 
one has learned.

However, as I worked through the material, I found that the comparability of the two courses ended with the content, philosophy, and 'lineage' they shared. If anything, the courses serve as contrasting ways of understanding and responding to violence and vulnerability. Also, the women's course could be seen as having a second 'lineage' based on women's self-defence and martial arts conferences attended by Sensei Tasha over the years she spent developing and refining the course while managing and teaching karate at her dojo. With these notes in mind on the exigencies of treating two very different courses together, now let us enter the field.

The dojo is small; the training hall taking up a small storefront in a strip-mall, and the office taking up another, with a small restaurant in between. It is located in a small town outside of the city where the summer course took place, and the classes tend to mainly be comprised of the local families in the neighbourhood; bully-proofing classes for boys and self-defence classes for girls and women are offered alongside the karate, wushu, and yoga classes offered for the entire family. Sensei Tasha's self-defence classes 'stem' from Sensei Ray's teachings, but her martial arts lineage stems from a female Modern Arnis (short-stick fighting) Master who also teaches at the dojo from time to time (personal communication, Nov.15, 2012). Sensei Tasha, in addition to teaching selfdefence, teaches karate, and the same terminology used in her martial arts classes is borrowed in the self-defence classes:

- Dojo (training hall)

- Sensei (teacher)

- Renshi (assistant instructor)

- Senpai (senior student) 
The women's course took place in a rented boardroom at a local university over eight weeks during the summer; a one-hour session once per week, and also included The Gift of Fear and Other Survival Signals that Protect Us from Violence by Gavin de Becker, as well as other assertiveness-training handouts.

It was a small class, and would get smaller over the summer. At the start were four instructors including Sensei Tasha; Renshi Abby, who worked in a factory; Renshi Diane, who had started taking Karate at Sensei Tasha's dojo after enrolling her kids; and Renshi Angie, who taught full time at the dojo.

The students were comprised of two students involved with a campus sexual assault support program, including Jen (long blonde hair, smiley, wanted to work in a women's shelter, doing her social work degree) and Sarah (sexual assault support program facilitator); two young women (Ella, short dark hair, worked with a student activist group, had finished her MSW) and Carmen (long dark hair, 4th year in an undergraduate program, wanted to go travelling, so that's why she wanted to take selfdefence); Leah - a young professional who always wore suits and had 'taken self-defence before'. Two other participants joined us over the summer; Claudette, Jen's mother, who came to the class to support her daughter and to learn some self-defence, and Maureen, an elderly woman with some physical disabilities and a lot to say about being attacked, harassed, and mugged in broad daylight.

Ella and Carmen were both planning on travelling to Europe, and both emphasized the need to take care of themselves, being able to address potential violence in different countries, especially when travelling alone. Leah had taken the class during 
the springtime, but hadn't been able to take every class, and wanted to catch up. Sarah, the facilitator for the sexual assault support program, was interested in sourcing an alternative self-defence class for students on campus, feeling that the university's selfdefence program didn't really address the more systemic issues with gender-based violence, and finding that women she spoke with who took the class, tended to come out of it feeling more afraid than before they went in.

"That happens a lot", Tasha said. "A lot of courses start in on the physical techniques without first looking at why we're taking self-defence, or they're taught in a way that doesn't address the issues survivors face when they decide to take the class. A lot of women end up feeling more fearful and disempowered coming out of them." She paused.

"What is self-defence?"

We looked around at each other. I held onto my immediate thought of the ability to set boundaries and enforce them. Ella spoke first. "I'd say it's building self-confidence... empowerment?" We looked around the room again. Sarah mentioned the negative connotations of 'self-defence' as a movement-what kind of self-defence? The feminist kind, or the kind that told women not to talk back to men? Jen said, on the one hand selfdefence offered the potential for confidence and physical capability, but agreed with Sarah that many 'self-defence' classes for women, and women's safety initiatives in general tended to inculcate the opposite. Carmen said self-defence was, for her, about having some physical capability, techniques, and confidence to be out after dark.

"Those are all good," Tasha said.

"My idea of self-defence comes from there, but also from knowing that while we might want to be aware of our surroundings and take precautions if that's what makes us comfortable, if something happens it's not our fault. Self-defence should not be about making women more fearful of being out there in the world. You have a right to be there. And if anyone dare treat you badly, or lay a hand on you, or try to hurt you, you are going home. You're going to walk away."

With that, and some exercises to get us thinking about targets on the body and how to either protect or attack them, our time was up for the day.

Each week, Sensei Tasha had us read chapters from Gavin de Becker's The Gift of Fear and discuss our readings the following week. Over the course of the summer, the question of what self-defence was became a recurring theme until something like the 
following definition came about: Self-defence is the willingness and the ability to set boundaries, maintain them, and stay safe.

\subsection{Perceptions of Stranger Danger}

The women's self-defence class could have been mistaken for a support group had it not been for the occasional shouts of 'NO, HANDS OFF', or the sounds of elbows, knees, and the heels of our palms striking targets held up by instructors cheering students on. What we discussed most often was intimate-partner violence, sexual violence, and finally workplace or street harassment. Discussions of street harassment tended to revolve dialectically between experiences of being harassed and the notion of stranger-danger, which continues to form a significant part of women's safety discourse. It strikes me that where strangers and women are concerned, the danger is mostly in what is termed street harassment. Women often find themselves bombarded with media messaging about their own vulnerability, be it in terms of date rape, or in terms of not going out late at night, but such discourse ignores who actually is vulnerable, why they are vulnerable, and how.

Jen, one of the students in the women's class, pointed out that while stranger-

danger is a legitimate concern, knowing what it actually looks like would be more useful for women to stay safe. In one of our conversations, she described an experience of street harassment:

"When I was 13, a man followed me around in his car. I was walking to a friend's house and he slowed down and followed me, asking if I wanted a ride. I kept saying no... He followed me later, same guy, same car, asking if I wanted a ride while I was on my way home from my friend's house..."

In class, Maureen shared with the group that she had been attacked outside her home, on 
public transit, in a parking lot, just outside of a store, and that three of the times she had been attacked, she had been in her wheelchair. All of the attacks had come from strangers, usually for money or cigarettes.

In the case of low-income women, or in the case of young girls, there is vulnerability to be found in the public sphere, and though strangers present the most immediate risk, their vulnerability arises from both the structure of their lives (Stanko 1988), as well as wider public discourse that tends to erase them by framing women's safety discourse in terms applicable to white, upper/middle-class, college-or-university educated women. Sylvia Burrow discusses this in her 2008 work on self-defence as a tool for cultivating autonomy, but she only offers that self-defence classes might seem elitist in that they incur a significant burden of time and money for those with a low income (Burrow 2008: 138). It strikes me that while discourses of vulnerability can be critiqued from a feminist-self-defence standpoint; vulnerability operates in multiple ways, where stranger-danger might be expressive of a larger problem of structural vulnerability.

We talked about other attitudes that might hinder a woman's ability to defend herself by redirecting her attention away from her actual vulnerabilities and towards doing emotional labour for others, or towards vulnerabilities that do not exist in that woman's life. Around the circle we shared the sort of things we tend to hear from friends, family members, teachers, co-workers, and workplace and university safety bulletins:

- be fearful, don't be reckless, be home before a certain time, tell us where you're going, go with a buddy, carry a whistle

- but don't lock yourself up in your house or live in fear, how can you live like that?

- don't wear that - too short, too bright, too much (makeup), or too 'outlandish'

- don't get people angry, nobody likes a bitch, watch your tone, don't be rude

- you can't defend yourself

- one of Sensei Tasha's recent self-defence classes she taught at a local high 
school involved this trope explicitly: the mother of a 15 year old girl refused to sign her daughter's permission form because she didn't want her thinking she could actually defend herself if a man tried to hurt her - why would you need self-defence, men only rape the pretty ones

- don't tattle about misunderstandings, but speak up and tell if someone hurts you 
However helpful (or not) each piece of advice might have been to the group members, taken together, we can see a pattern emerge: of attempting to close these women off from social lives, from lives outside home (conceived of as 'safe'), and from their own experiences ('just a misunderstanding'). When I spoke earlier of living within emotional categories and vulnerability, this is what I meant - the group's experiences had been framed in such a way as to delegitimize their lived concerns and cut them off from their experiences of what safety/threat actually were ('how can you feel unsafe, you're at home'/ 'you can't defend yourself'/ or the poisonous 'why would you even want to defend yourself?'). The advice given to the women is not so different from the interventions named in Stanko's (1988) work, and not so different from what Martha McCaughey refers to as 'traditional women's self-defence' (1998), which Jill Cermele describes as reinforcing traditional gender socialization through what looks like riskmanagement, but in practice turns out to be an exercise in hyper-vigilance (Cermele 2004).

After we came up with the list, some of the students had comments. Ella compared labeling the advice and highlighting its problematic aspects to "naming the behaviour' - a technique taught to women in domestic violence shelters, specifically one to give them a language to talk about abusive behaviours and abusive patterns they saw, whether from partners, family, co-workers, or even in themselves.

Jen mentioned in one of our conversations that what interested her in taking the self-defence class was, in part, its feminist leanings, saying that "Self-defence tends to put the burden on women, teaching them 'how not to get raped', and there's a lot of victim-blaming. When I heard about this course, I was very excited. I also like that there would be a component for discussion and thinking 'self-defence' 
instead of just physical techniques - the problem with those is, unless you practice them often, you forget".

Sarah, one of the university student group leaders in the class, had also said something similar in a critique she had of the university's usual women's self-defence training program:

"I'm hoping this class will show the university that there's another way to teach women to defend themselves, a way that doesn't depend on teaching them things like 'be afraid, carry a whistle, walk with a buddy, and oh by the way, knee them in the groin.",

"Doesn't the university program teach students a lot of techniques, and encourage them to respond to aggression with the same?" I asked.

"Sure, they do. But they don't also teach *why* we're learning, you know? They don't give women a language to talk about the kinds of stuff they're learning, and there are a lot of students who wouldn't want to go in the first place."

I glanced at one of the class flyers taped to the whiteboard at the front of the room. In the corner it bore interlocking gender and transgender symbols in the colours of the rainbow. I looked back to Sarah. "LGBTQ students?"

Sarah nodded.

"How come?

"It's pretty high-stress, and it also really glosses over the dangers different women facelike you said, LGB folks, or women of color... at the same time, they're being bombarded with all this info about what to do in this situation or that situation, but no one s putting it together."

For Sarah, putting it together still meant learning physical techniques, or situational skills, but it also meant some of the exercises we would do over the course of the summer: examining the behaviours we learned outside of class, 'comparing notes', and tracing out the helpful ones from the self-defeating ones. It also meant an instructor or class facilitator explicitly referring to those times when openly or aggressively defending oneself was not the safest option - as it might not be for a woman of colour, or LGBTQ person, particularly should law enforcement become involved (personal communication, Sarah, July 9, 2012). Again, such vulnerabilities arise structurally, where for white, heterosexual women, stranger-danger is somewhat less of an issue because of their location within a social structure designed to include them and hold them in contrast to 
'dangerous Others', or Others who are not represented in the dominant discourses of women's safety.

We re-wrote the list, removing the references to appearance, to vocal tone, and directly countering the 'you can't defend yourself' as well as the 'why would you need to defend yourself?' messages. Renshi Abby spoke to the last one, saying that day someone had tried that line on her when the topic of self-defence at Sensei Tasha's dojo came up in the conversation. "What did you say to them?" Carmen asked. Renshi Abby winked. "I said 'you, that's why!', and walked away! The guy tries to bully all the gals at work." She laughed and shook her head.

The messages that felt to be useful looked more like the following list created around the circle, starting with the instructors and working its way around the room:

- You can defend yourself. If you can't at the moment, it's not your fault if you get hurt - Anyone feeling at risk of being attacked, or bullied, or abused needs self-defence

- Use whatever 'voice' you need to tell an attacker to stop what they are doing, and the louder the better

- Be aware of your surroundings, but don't jump at every little thing. Most of the threats 'out there' are not from there, but from relationships we are already in.

This list aligned better with the aims of the group - to not be afraid, but to learn that they could address and stop a violent situation, as well as get to safety. As much as the first list aligns with traditional self-defence models explored in previously mentioned literature, the second aligns with what McCaughey calls 'feminist self-defence', and Sensei Tasha herself indicated that at one of the conferences that led her to develop the course, she had picked up on some of the feminist language that spoke directly to 'naming behaviour', to female capability for self-defence, and to the wider applicability of 'anybody being abused needs self-defence'.

We started our lessons with a focus on being aware of surroundings, and I will revisit the topic again, as there are two aspects to this. First was the language we used, which 
took the idea of physical awareness and codified it. The second aspect came about from the practice of using this code in daily life to assess one's responses to their surroundings. Before I describe the awareness exercises, let me first attend to the concept of attention.

Taking the body as object, and taking this point to the process of attending to and objectifying bodies, Tom Csordas defines somatic modes of attention, contrasted with attention-as-disembodied-gaze (Csordas 1993:138), which broadens the field in which we can look for phenomena of perception, attention, and engagement with the world (Csordas 1993: 138-139). In the context of a self-defence class, we learn to attend not just with hearing or sight, that is, by listening to an instructor or watching a technique being performed; but we learn to attend to our surroundings with all our senses - including 'the sixth sense', which could be characterized as a unity between both senses and our willingness to attend to them. This unity-of-sense and of response is often framed as intuition; that visceral sense one might experience in response to danger - and it is this sense in particular that we worked on in the women's class: first by learning to 'filter out' where threats were most likely to come from, then by learning to respond effectively to our own signals (usually a fight/flight response).

\subsection{The Gift of Fear: Understanding the Signals of Vulnerability to Violence}

We also discussed Gavin De Becker's book whenever different themes came up in the discussions, and one of the first themes we discussed (and would return to often) was that violence was not something so far outside of everyday life that we could justify ignoring it. Sensei Tasha addressed such myths early on, and often, in the women's class, drawing on examples, tools, and concepts from Gavin De Becker's Gift of Fear, such as turning 
intuition, understood as totality of the senses that takes into account a person's behaviour, one's own bodily responses, and the situational context, into a set of tools for understanding, predicting, and escaping potential or imminent violence.

These tools included 'pre-incident indicators' (PINs), or “those detectable factors that occur before the outcome being predicted" (De Becker 1997: 20), which spoke again to the aforementioned contextual cues. Let us consider for a moment an example from De Becker's book in which a young woman, trying to make sense of a stranger-based sexual assault that nearly resulted in her murder, describes several of these factors:

She climbed the few steps to the apartment building door and closed it behind her. Next came the four flights of steps. Near the top of the third landing, one of her shopping bags gave way, and cans of cat food tumbled down the stairs....

"Got it! I'll bring it up," someone called out. Kelly didn't like that voice. Right from the start something just sounded wrong to her, but then this friendly-looking young guy came bounding up the steps. He said, "Let me give you a hand."

"No, No thanks, I've got it."

"You don't look like you've got it. What floor are you going to?"

She paused before answering him. "The fourth, but I'm okay, really."

He wouldn't hear a word of it.... "I'm going to the fourth floor too," he said, "and I'm late - not my fault, broken watch - so let's not just stand here. And give me that." He reached out and tugged on one of the heavier bags she was holding. She repeated, "No, really, thanks, but no, I've got it."

Still holding on to the grocery bag, he said, "There's such a thing as being too proud, you know."

For a moment, Kelly didn't let go of that bag, but then she did, and this seemingly insignificant exchange between the cordial stranger and the recipient of his courtesy was the signal - to him and to her - that she was willing to trust him. As the bag passed from her control to his, so did she.

"We better hurry, he said as he walked up the stairs ahead of Kelly. "We've got a hungry cat up there."

Kelly was now standing at the door to her apartment, which she'd just opened. "I'll take it from here," she said, hoping he'd hand her the groceries, accept her thanks, and be on his way. Instead, he said, "Oh no, I didn't come this far to let you have another cat food spill." When she still hesitated to let him in her door, he laughed understandingly. "Hey, we can leave the door open like ladies do in old movies. I'll just put this stuff down and go. I promise." She did let him in, but he did not keep his promise. (De Becker 1997: 2-3)

"Kelly had been apprehensive from the moment she heard the stranger's voice, 
and now she wants me to tell her why. More than anything else, it was just the fact that someone was there, because having heard no doors open before the man appeared, Kelly knew (at least intuitively) that he must have been waiting out of sight near the entry hall. Only as we spoke did she realize that when he said he was going to the fourth floor, he didn't offer why. It was Kelly who had filled in the blanks, concluding that he was visiting the Klines, who lived across the hall from her. Now, as we are talking, she realizes that if the Klines had admitted a guest over the intercom, she'd have heard the loud buzz of the electric lock being released, and Mrs. Kline would have been at the top of the stairs, already well into a high-volume conversation with her visitor. It was because of all this that Kelly's intuition sent her the signal to be wary" (De Becker 1997: 65). 
The contextual cues highlighted by Gavin De Becker included, among those situational ones described by Kelly (the aggressor did not offer an explanation of why he was going to the same floor as she was, there was no evidence that her neighbours were waiting for the aggressor), several strategies De Becker says are used by aggressors. In the example above, we can see four at work - "discounting 'no"' (Kelly refused assistance twice), "too many details" (the broken watch), "charm/niceness" (unsolicited offers of assistance), and "loan-sharking" (the aggressor helps Kelly with her groceries to put her in 'debt', and 'collects' by entering her apartment, sexually assaulting her at gunpoint, and attempting to murder her) (De Becker 1997:65-68).

For De Becker, whose examples and conceptual tools provided the background for the discussions in the women's class, violence was something that could be not only understood, but predicted, with careful attention to situational context, interpersonal cues (such as those mentioned above), one's bodily responses to these, and even to how socialization came into play in such interactions: a recurring theme in Gavin De Becker's book was of women's socialization to value smooth social interaction over being seen or treated as a 'cold bitch' for explicitly rebuffing unwanted attention, and how that socialization worked against the instinct to protect oneself.

All of this went towards demonstrating for the reader a way in which violence could be understood after the fact, and a violent event in one's life could be analyzed, framed, and presented back to the reader as a model for addressing future vulnerabilities based on certain elements - the situation, the aggressor's behaviour, and one's responses to it. In other words, Gavin De Becker's broader message is that violence, and the vulnerabilities associated with it need not be beyond the realm of understanding. 
Gavin De Becker believes that understanding violence is not only practicable, but imperative. His book is one of a small number in popular media disrupting what I would call the myth of the 'unintelligibility of violence', based on the question he repeats throughout his book. Each chapter he asks the reader 'who could have known?' after taking them through a logical framework which led to a set of likely outcomes - whether harassment, violence, or a de-escalated situation. The framework uses four elements: Perceived Justification-for violence, Perceived Alternatives-to violence, Perceived Consequences-for violence, and Perceived Ability-to carry out violence (De Becker 1997). The elements presented by Becker are used to determine the situation leading up to potential violence (or de-escalation), and are a tool-set for thinking over longer time periods, compared with the pre-incident indicators: but both tools, along with the predatory behaviours named by De Becker, are still directed towards allowing a reader to understand ongoing or potential violence (or vulnerabilities) in their lives - and thus, to respond appropriately. Over the course of the summer, we conducted role-plays of different scenarios intended to use these conceptual tools - but first, we needed to frame our own thinking about what different behaviours and situations 'counted' as violent or threatening.

We began with the following exercise:

In the second week of the women's class, we were still a full group, between the instructors (Sensei Tasha, and Renshis Abby, Diane, and Angie) and the students (myself, Carmen, Ella, Jen, and Maureen). Sensei Tasha handed out a set of small placards, sticky notepads and pens for writing, and cleared off two large tables at the front of the room. On the tables, she placed her own three placards: 'bothersome', 'dangerous', and 'life-threatening'.

Sensei Tasha looked at us.

"I want you to write down some violent, or threatening behaviours you have seen, experiences you have had, or even violence you have learned to be fearful of, thanks to the media - but only in one word. You can use as many of the sticky notes as you want- 
and then you're going to place your words under these placards. Like... bullying, for instance" She wrote the word 'bullying' on her own sticky notepad and stuck it to the table below 'life-threatening'.

"Some of these might fall in the three categories differently depending on age, race, ability, sex, and gender," she continued.

"Like... 'Racism' might fall under dangerous or life-threatening for a person of colour." She wrote 'racism' on one of her sticky notes and placed it on the table under 'life-threatening'.

With that, we broke off into pairs; I paired up with Ella, Jen with Maureen, Carmen with Renshi Diane, and Renshis Abby and Angie together. Sensei Tasha went over to Maureen and Jen and sat with them. I looked at Ella and said "hmm ...street harassment?" I wrote it down. We continued back and forth, from the other pairs I occasionally could hear 'hitting', 'biting', from Maureen I heard 'break and enter'.

"I'm about to run out of room here!" Ella laughed, putting sticky notes on her arms with words like 'bullying', 'verbal assault', and 'rape'.

"Hey, arms, that's a good idea. Y'know... it doesn't affect us, but I wonder if we can say things like genocide? We do hear about it," I said.

"Why not?" Ella countered. We got up and began placing our sticky notes down on the table, from 'bothersome' to 'dangerous' and 'life-threatening'. Other participants began to crowd around the table, forming a collective mental map of showing where the words fell on the spectrum of violence from micro-aggressions to deadly force. A stack of laminated placards sat beside the sticky-note covered table.

Sensei Tasha called the group to attention.

"I want you to each take from the pile of cards here... and you're going to read them out loud, then put them where you feel they should go-bothersome, dangerous, or life-threatening." She began handing the placards out.

We each ended up with about three, and around the group, still standing at the table, we read them out loud and placed them on the table. Where the sticky-notes had been single words, these were short phrases, like 'makes me feel stupid', 'hurts my pets'/ 'kicked my dog', 'makes me lie for him/her', 'pushes me to drink/do drugs'. I went first, with a placard reading 'makes me lie for him', and placed it under 'bothersome'. By the time the group finished, the tables were covered in sticky-notes and placards. I hastily took a photo of the tables and the results looked something like the following.

\begin{tabular}{|c|c|c|}
\hline Bothersome & Dangerous & \begin{tabular}{|l} 
Life-Threatening \\
\end{tabular} \\
\hline $\begin{array}{ll}\text { - } & \text { (2 sticky notes) Racism } \\
\text { - } & \text { (2 sticky notes) Bullying } \\
\text { - } & \text { (2 sticky notes) Verbal or } \\
& \text { emotional assault } \\
\text { - } & \text { Yelling } \\
\text { - } & \text { Makes me feel stupid } \\
- & \text { Makes me feel bad about } \\
- & \text { myself } \\
- & \text { Told other people I had } \\
& \text { slept with him/her }\end{array}$ & $\begin{array}{ll}- & \text { (8 sticky notes) Rape } \\
- & \text { (4 sticky notes) Sexual } \\
& \text { assault } \\
- & \text { (3 sticky notes) } \\
& \text { Bullying } \\
- & \text { Refuses to wear } \\
& \text { protection when we're } \\
& \text { having sex } \\
- & \text { Physical Assault } \\
- & \text { (2 sticky notes) Kicking }\end{array}$ & $\begin{array}{ll}\text { - } & \text { (3 sticky notes) } \\
& \text { Genocide } \\
\text { - } & \text { (5 sticky notes) } \\
& \text { Rape } \\
\text { - } & \text { Colonization } \\
\text { - } & \text { Murder } \\
\text { - } & \text { Physical abuse } \\
\text { - } & \text { Hurting pets } \\
\text { - } & \text { Pushes me to } \\
& \text { drink/do drugs }\end{array}$ \\
\hline
\end{tabular}




\begin{tabular}{|c|c|c|}
\hline $\begin{array}{ll}- & \text { Isolation } \\
- & \text { Kicked my dog } \\
\text { - } & \text { Makes me lie/cover for } \\
\text { him/her } \\
\text { - } & \text { Insists on paying on a } \\
& \text { date } \\
\text { - } & \text { Theft } \\
\text { - } & \text { Stares at me } \\
\text { - } & \text { Street harassment } \\
\text { - } & \text { Forced me to kiss } \\
\text { - } & \text { him/her } \\
\text { Always calling and } \\
\text { checking up on me }\end{array}$ & $\begin{array}{ll} & \text { Hitting } \\
\text { - } & \text { Biting } \\
\text { - } & \text { Punching } \\
\text { - } & \text { Systemic racism } \\
\text { - } & \text { Follows me to my car } \\
\text { - } & \text { Prevents me from } \\
& \text { working } \\
\text { - } & \text { Seizes/takes my } \\
\text { - } & \text { paycheque } \\
\text { - } & \text { Alway \& enter } \\
& \text { late at work when others } \\
\text { have gone } \\
\text { - } \quad \text { Mugging } \\
\text { - Threatens to take the } \\
\text { kids } \\
\text { Pushes me to drink/do } \\
\text { drugs }\end{array}$ & - $\quad$ Theft \\
\hline
\end{tabular}

Table 1: Bothersome, Dangerous, Life-Threatening

The bothersome/dangerous/life-threatening exercise spoke to the types of violence the women in the group found themselves vulnerable to in their lives, and even to their very perceptions of vulnerability. For example, what many of the group labelled 'life-

threatening' spoke to our socialization in a culture where sexual attack does change who you are (by rendering victims 'despoiled' through discourse that continues today) but also to a given participant's experiences of that socialization, or that form of violence. At the same time, Sensei Tasha reiterated that sexual assault was not in itself life-threatening, only that we had been taught to see it that way (personal communication, July 9, 2012).

Again, here we might say that violence rendered unintelligible by multiple definitions of what counts as violence, creates a heightened sense of vulnerability to such a point that it can interfere with one's ability to respond effectively to threats. Granted, as a class of mostly university-educated white women, words like 'genocide' and 'colonization' reflected more our academic backgrounds in various social sciences, while words and phrases pertaining to sexual assault, bullying, harassment, and abusers forcing 
us to lie for them spoke more to lived realities or media stories - particularly fear of rape, given that in a group of eight women including instructors, the word 'rape' was written down a total of thirteen times and distributed throughout the 'dangerous' and 'lifethreatening' categories.

This is the sort of ongoing, low-grade anxiety masked as fear that Gavin De Becker discusses in his book, and contrasts with the fear (fight/flight) response which, under the right circumstances, proves a powerful ally in self-defence.

\subsubsection{Responding to the Signals of Violence and Vulnerability}

In the advanced course, it went without saying that violence could be understood, approached, addressed, and put away, given that many of the participants took up the theme every day either through their jobs, or through martial arts. The advanced course took place from September through November at Sensei Tasha's dojo: Twelve weeks of 90 minute classes, plus handouts excerpted from Canadian security personnel training manuals such as the Canadian Use of Force System. It was another small class, about ten students: Steve, a university student; Nathan, a short, middle-aged Renshi at the dojo; Albert, a paramedic and military reservist; John, a martial arts student; and Fred, another martial arts student. The women in the class were either assistant instructors, like Renshi Marta, who taught a morning class; or senior martial arts students, like Senpai Tammy, who also worked with Albert as a paramedic; Senpai Elena, another senior student; and myself. The instructors, besides Sensei Tasha, were Sensei Ray, a retired police officer; Sensei Bruce, a police officer; Sensei Ted, another police officer; and Sensei Sally, who taught morning classes at the dojo with Renshi Marta. 
I arrived to the program at the end of one of the dojo's Modern Arnis classes

(Modern Arnis being a stick-fighting style using light bamboo sticks in place of shortswords). Ten of the Modern Arnis students remained afterward for the self-defence class. Unlike the women's class I'd attended in the summer, the class was made up almost entirely of practising martial artists, except for me. Besides being out of shape, I had not trained for fifteen years, and would need to work that much harder to keep up both with the physical pacing, and with the embodied attitude of being able to respond easily and forcefully to violence - often in spite of physical pain or fatigue.

"What stance are we in?" barked Sensei Ray.

"Utility stance," we said in unison.

"What are our color codes of awareness? White means -"

"Oblivious!"

"Yellow means -"

"Aware!"

"Orange means-"

"Potential threat identified!"

"And red?"

"Engaged!"

"And should you go out in public in white, and I don't mean white after Labour Day?" "No!"

We stood in a line in front of the mirrored wall of the dojo, feet lightly on the ground, hands in front of us, palms touching lightly. Sensei Ray's class often felt like military drill, with the class forming a line on one side of the dojo and Sensei Ray in front of us, demonstrating, telling us stories and scenarios for using the Defendo-like form of self-defence he taught. As far as he was concerned, there were no non-martial artists here, however long we may have stayed away from a dojo. The physical and emotional capability to defend oneself vigorously was the assumed default here - not surprising, given how many police and military, retired or otherwise active, were taking the class.

We started on skills right away, talking about colour codes of awareness from white (unaware) to red (immediate danger/engaged in the situation). We practiced hitting (not 'strikes', just trying to hit or block/swat away) - I partnered up with Fred, a tall, smiling man wearing glasses. We dodged around each other, beginning to trade blows and blocks. As we worked, I could 'see' the giveaway movements that told me when to hit and surprise, or get my hands up into a flinch-block.

"Wow, you're fast," Fred said, smiling. I laughed and leaned back slightly to the left as if about to wind up for a swat at his arm, and jabbed at his throat instead with my right. "See?" he asked. I blushed again. 
Merleau-Ponty writes that "the visual thing, or the tactile thing, which remains for us the same throughout a series of experiences... is that which is met with or taken up by our gaze or by our movement, a question to which they respond precisely" (Merleau-Ponty 2012: 331).

In the hand-to-hand training sessions, the 'question' is asked, I think, by both partners - one tries to grab or pinch the other; the other tries to escape; one tries to bring the other to the ground, and when she can't, the other 'helps' by giving a kick or another such movement to demand a response, as will be seen shortly in my practice with Albert. Merleau-Ponty writes that “...each bodily stimulation for the normal subject awakens, not an actual movement, but a sort of 'virtual movement'; where it can...apply its activity to the stimuli that are inscribed upon its sensory surfaces..." (Merleau-Ponty 2012: 111). Recall my discussion of Jaida Kim Samudra's notion of 'somatic interviews' in which the anthropologist taking up a physical practice would 'ask' questions through the body by moving a certain way so as to provoke a response. Somatic interviews came up as a practice quite often throughout the advanced self-defence course, more often than in the women's class, which did not emphasize physical techniques as much. When I first began to learn the techniques applied in the advanced class, it was a little like learning two similar languages at the same time: although I had not trained in martial arts in fifteen years, whenever I would attempt the techniques in the self-defence class, what 'came out' was usually a hybrid of the technique I was trying to use, and some older, seemingly-forgotten technique more appropriate to a Taekwondo sparring session. The result was such that the movements of self-defence were somewhat abstracted from what 
we were trying to accomplish. For me, this meant sometimes asking instructors to perform techniques on me before I attempted them, so I would know how the technique 'should feel' on the receiving end. Other times, however, instructors and fellow students took a more pragmatic approach - as in Albert's kick to get me to move into a better position to execute a takedown.

I was getting Albert to bend at the waist but couldn't bring him to lie face down on the floor. Pulling at his arm only led him to walk awkwardly to his side, towards me. Sensei Ted circled around us to see how we were doing. "Marion, You're too close, step back from him. You got him, now-" He paused and pursed his lips. "Albert, give her a kick." As Albert's foot came out, I jumped back, his arm still in my hands, pulling him down so his arm was straight-almost locked. "Better! Now don't lock the arm-just walk him a couple steps - stay back - give her another kick if she gets too close!" I walked two steps to my left, bringing Albert down to a prone position on the floor.

In the dojo, we are asked to move, do, and respond in ways far enough outside our experience that the movements themselves are abstracted concepts before they are taken up into the body's habits: that is to say, we may know how to throw a punch, or kick our feet, but we are not doing that in the classes here. Here, we are using relatively few techniques designed to disarm or disable an attacker, and often to do so at nearly fullcontact, leaving welts and bruises, and working past the pain of those - simulating combat as closely as possible in order to train our responses in such situations.

We are asked to fight with open hands, in crouched stances that make clear that we are the victim being transgressed upon - a performance for potential cameras that may catch us in the act of defending ourselves - a performance that may need explication to law enforcement, or in a courtroom. There is no question, for our purposes, that we can defend ourselves to begin with; the entire set of movements is about both managing 
aggression and appearing to do so, for the sake of defending our bodies in the moment, and potentially defending ourselves as socio-legal persons at a later time.

We were working, and Sensei Ray stopped the class: people weren't moving around enough. "Don't play patty-cake. I don't want any of this 'stand in one place trading blows' like they teach you in martial arts. Nothing against martial arts. I'm a martial artist myself. But we're not in the dojo here, this is the real world. Move around. Use your peripheral vision. You will see in that split second what the other guy is going to do. Fake him out, stare up at his face, and in your periphery, do you SEE his hands start to move? Do you SEE the weight shift, the shoulders drop, the head tilt? Don't just SEE it, react!"

He called up Sensei Ted to the front of the dojo. Sense Ted tried to grab him, and each time his hands got near, Sensei Ray either swatted his hand away or grabbed his fingers. Sensei Ted tried faking Sensei Ray out - moving with his right, and then grabbing with the left. Sensei Ray grinned and moved out of the way.

"Don't just react, respond." He grabbed Sensei Ted's hand by two fingers and guided them around in a tight circle, bending his fingers back as he went until the palm of Ted's hand faced up, and his fingers were bent backwards, pointing down towards Ted's feet. Ted blinked hard and rose up on his tiptoes, and as Sensei Ray gave a nudge to his left, Ted moved towards the pain in his body. Sensei Ray pushed Ted directly back, and Ted moved backward. Sensei Ray leveraged Ted's fingers to make him follow the pain and stand up on the tips of his toes before letting go.

Sensei Ray's class focused on the situational aspects of violence, and those physical techniques introduced in the women's course were developed further here. Where the women's class tended to give a broader picture of the structure of women's lives in general, and of some different ways to respond to this generalized sense of vulnerability, the advanced class focused on interrupting the immediate situation of violence and escaping from it.

\subsection{Codifying Vulnerability}

Over the course of the summer, the women's class built up a set of relational techniques for participants, which could then be used creatively: identifying the threats that had piqued a given woman's awareness of self or surroundings in the first place and then 
responding accordingly, knowing that they might escalate or de-escalate their responses to those situations. The colour-codes in particular gave participants a language with which to express their safety concerns in a sequence fairly similar to the Canadian Use of Force System used in the advanced class to describe the escalation of a confrontation. The illustration below is the Use of Force model handout provided during the advanced class, and serves the same function as the colour-codes of awareness: to give practitioners a language with which to speak about how conflicts escalate, to show the internal logic of how conflicts escalate to violence, and to give practitioners a way to tie this understanding in to their own physical responses during a conflict.

Granted, the Use of Force model, like the physical techniques learned in the advanced class, is a tool used in the Security professions - and reflects that language. This cycle of escalation, along with the colour codes (white, yellow, orange, red), form a logic intended to show concretely that concern over safety does not 'come from nowhere', or 'only as a result of past (individual) trauma', but that it comes as a result of behaviour existing along a spectrum. Being able to address aggressors' behaviours along a spectrum of violence in a concrete way does give self-defence participants back some sense of control over situations in the world 'out there' beyond the training hall. 


\section{National Use of Force Framework Le cadre national de l'emploi de la force}

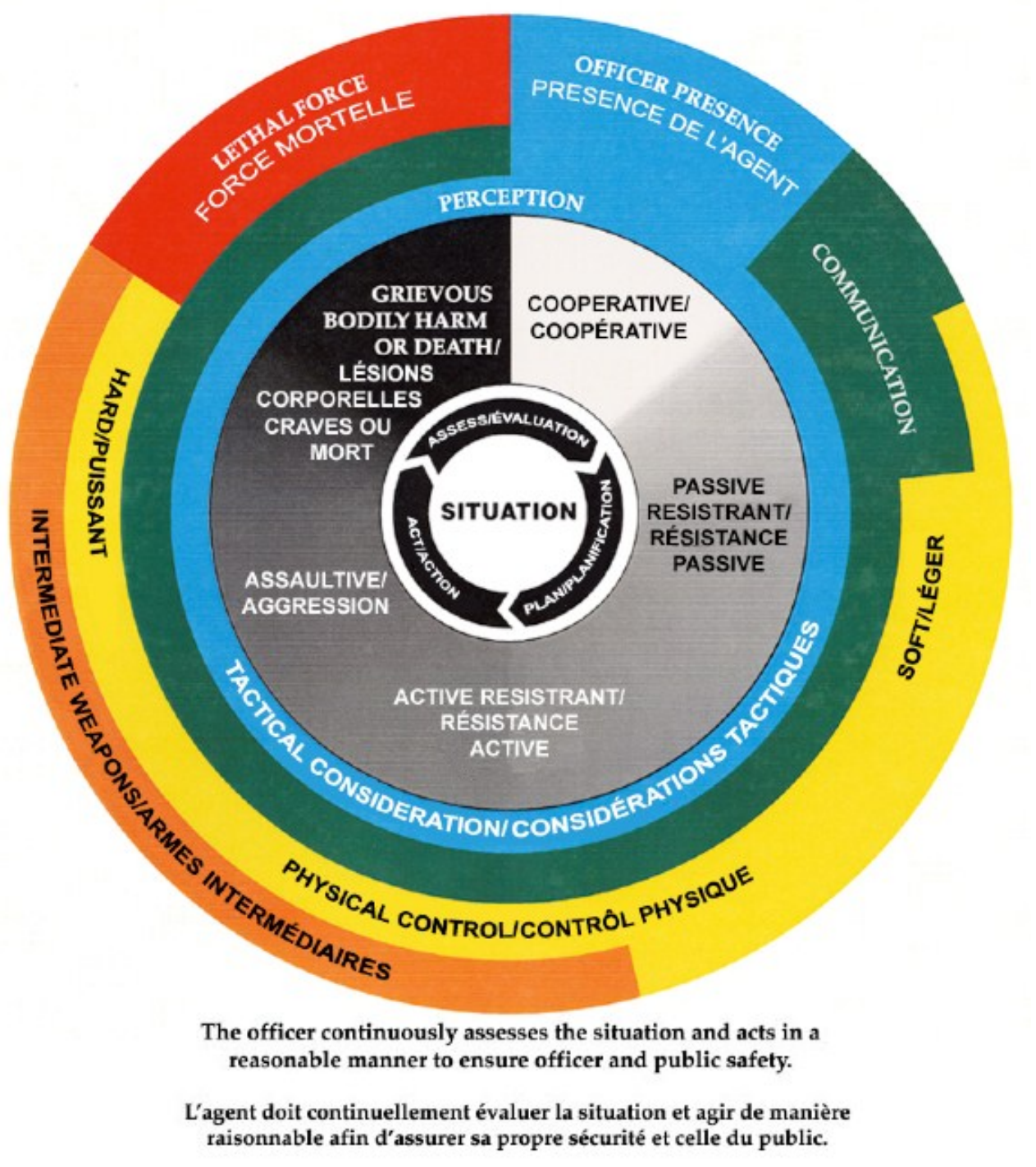

Illustration 1: Canadian National Use of Force Model $^{2}$

The colour-codes of awareness themselves, however, serve as a sort of metaphorical

device for the feelings one experiences in response to a given situation, but also serve as a focal point. Colour-codes stand in for certain emotions or immediate responses to a given situation or threat, and they are meant to train the practitioner in how to attend to

\footnotetext{
${ }^{2}$ http://www.cpc-cpp.gc.ca/cnt/tpsp-tmrs/cew-ai/cew fin_rp-eng.aspx\#figure1
} 
their body in a particular way: to try to 'perceive oneself in the process of perceiving' (Merleau-Ponty 2012:247) and put that objectification of one's own body to use in protecting oneself - and in 'objectivizing' the emotions or responses themselves.

By turning their attention to feelings of anxiety, or even just 'noticing funny things that raise your awareness level', practitioners attempt to become sensitive to both those occurrences which pique their awareness, and to the ways that awareness feels within themselves - usually anxiety, or an eerie feeling that something does not belong. They try to make this a habit, beginning with the earlier lessons of 'just notice when you feel yourself going into white (oblivious)' - in other words, the practitioner attends to the way they are attending to and engaged with the world at that moment. On its own, this seems like something that could be repeated until incorporated as a habit, but it strikes me that using it on a day to day basis is not as easy as merely having internalized that particular technique - unless one is attuning oneself to a particular mode of attention. Yet it strikes me that the ability to 'perceive oneself perceiving' in an instrumental way (as opposed to perceiving oneself perceiving in the case of pain/endurance) cannot last longer than a second or two, so the habit being formed is not so much learning how to perceive one's awareness levels changing, but in being sensitive to those changes in the first place. What is being trained is a particular kind of sensitivity to one's surroundings as well as to one's own bodily responses to them.

We worked with this system over the summer, beginning with 'just noticing' when we found ourselves 'in white' (oblivious) and working our way to being able to 'code' our awareness-levels throughout the day.

- White: oblivious, unaware of surroundings - example: walking with iPod cranked up. 
- Yellow: basic awareness of surroundings - example: walking with no music, aware of who is around us.

- Orange: heightened awareness, possible threat - example: noticing that person trailing behind

- Red: danger - example: being attacked

In Sensei Tasha's class, the discourse of stranger-danger met with the practice of colourcoding and attending to not fear or anxiety, but 'awareness levels', which took the emphasis off of encouraging a generalized hyper-vigilance, and put the emphasis on the bodily experiences of what one's awareness of one's surroundings did: for example, we discussed each week 'how our [previous] week was', and whether any situations had led to a piquing of our awareness levels - whether we had noticed ourselves 'slipping into white', or whether anything had given enough cause for concern to 'go to orange or higher'.

There was, however, a tension between attending to one's bodily responses to his or her surroundings and to other peoples' behaviours, and the stranger-danger discourse. Sensei Tasha continuously emphasized that even if we were not aware of our surroundings at the time of an attack, it was not our fault, there was still a strong urgency to the notion that one should never go out in public "in white", that is, unaware of our surroundings.

This urging leads to an impasse: if the bulk of the danger faced by women comes from the private domain of their intimate circles and sometimes their workplaces (Stanko 1988), why the continued emphasis on the public sphere as a space of danger? Here, then, is one of the ways the ongoing discourse of public space as a space of risk and potential danger for women continues to undermine the lessons they learn in self-defence: instead of focusing on awareness in the home, for example, or awareness in the workplace, the 
course recapitulates the stranger-danger myth. Taking into account that most victims do not report their assaults, according to Statistics Canada, as of 2011, the most commonly reported perpetrators of violence against women were their intimate partners (45\%), (Sinha 2013: 8) with more than two thirds of reported violent incidents being committed in private residences (Sinha 2013: 14). The advanced self-defence class made the boundary between home (safety) and public space (potential risk) even clearer with the exhortation to "never leave the house 'in white'." Sensei Ray, on many occasions, would half-jokingly explain "the only time you should ever be in white is when you're at home, doors locked, windows shut, dog by your feet..." although it is worth mentioning that he was not speaking to a class of only women, but a mixed class comprised of participants for whom the private sphere would be conceived of as a safe space.

Both the women's and the advanced courses used narratives of 'safety' to highlight lived vulnerability in their everyday worlds (stranger-danger/intimate-partner danger), in one's affect (behaving like a victim), and the sort of vulnerability that arises from a threatening situation. Given my earlier discussion of where risk comes from for men and women alike, it seems worth taking a closer look at all three, as one of the (admittedly implicit) promises of self-defence is that participants can interrupt the vulnerability they have either learned to embody, to be fearful of, or to ignore.

For women, Martha McCaughey says, self-defence instruction can help "identify how sexist ideas find their way into bodily functions through (walking, talking, yelling or not), but also some of the mechanisms which create and sustain gender inequality by forcing women to act in unfeminine ways" (McCaughey1998: 281), which she presents as loud, aggressive, willing to celebrate one's physical strengths, and willing to respond 
to violence with the same (McCaughey 1997, 1998). Kristine de Welde's 2003 study follows a similar argument to McCaughey, towards a discussion of how self-defence training helps the women in her study "lay bare how their socialization to be feminine actually creates vulnerability and danger in their lives" (De Welde 2003: 256). However, De Welde says, in the process of redefining their positions as victims from negativevictim (weak, passive) to active survivor (with knowledge about perpetrators and how to avoid or respond to them), the women in the self-defence program she studied became more interested in redefining their femininity as opposed to simply 'unlearning' it (De Welde 2003: 273).

One such mode of redefining femininity might be in taking up or otherwise reconnecting with emotions which tend to be sanctioned against in women, and reconnecting with the responses associated with such emotions - for example, being explicitly angry at a boundary-violation, and expressing it openly; or rebuffing an unwanted advance, again, explicitly, and again, skipping levels of politeness as appropriate, should an aggressor continue to escalate his or her efforts. In the women's class, during our sit-down sessions, Sensei Tasha would often highlight this tendency by asking first about our weeks, and then about 'the kinds of ploys you run into', whether from strangers asking for the time, or from acquaintances drawing us into interactions that made us uncomfortable or frightened. During one such session, she asked us how our weeks had been, and Jen mentioned trying to break contact with 'a friend' who had been calling her at very late hours and sending her threatening text messages.

"How did that make you feel?" asked Sensei Tasha. Jen blinked and shifted in her seat. "Well he has some issues that we were working through, so, I know why he was calling, for support... I was maybe a bit frustrated, I guess?" I looked at her and caught her eye for a second. She paused. "Scared, actually. He's not a nice guy. I mean ... he's 
just not very well, that's all." Sensei Tasha nodded. "You were scared?" Jen shifted in her seat again. "Yeah, yeah, I was scared. And angry."

Making an active connection between the behaviour of others, and one's own feelings permitting oneself to feel or express, say, anger at an aggressor, can be difficult to do, given socialization to 'be polite', or even given what Merleau-Ponty describes as a general tendency for people to not experience their own feelings, "but rather to live according to the emotional categories of our milieu" (Merleau-Ponty 2012: 399). Merleau-Ponty's words have implications for emotional health, particularly for abuse survivors, when the emotional categories available tend to imply that one's emotions are not 'real' - that a woman is 'hysterical' rather than justifiably angry, or that she is 'dramatic' rather than anxious or frightened. In the women's class this came out also in our reading of Gavin de Becker, who writes of abuse survivors that:

"Being struck and forced not to resist is a particularly damaging form of abuse because it trains out of the victim the instinctive reaction to protect the self. To override that most natural and central instinct, a person must come to believe that he or she is not worth protecting” (De Becker 1997: 215).

In this reading, we see the importance of connecting with new categories by which to label one's emotions, and of developing the capacity to feel and express vigorously what De Becker says is the instinct to defend the self. For Jen, this could be seen as reconnecting with the anger at her 'friend's threats: anger is many things, but when the self is threatened, it is first and foremost a protective emotion. Self-defence offers participants the opportunity to interrupt a few aspects of the emotional vulnerability that stems from years of learning not to fight back when faced with aggression, by cultivating some of those more aggressive emotions themselves - at least in the women's class this was the case. 
The women's class tended to rely on discussion as the primary vehicle for learning in-class, with some techniques practiced in everyday life. For example, each week we would recall the colour codes of awareness from white (oblivious), to yellow (aware), orange (heightened awareness; possible threat), to red (danger), and discuss how the intervening days between classes had been; whether there had been any occasions for 'going into orange or red', whether we had noticed times we had 'been in white', that is, not paying attention to our surroundings.

This technique on its own, of attending to both one's surroundings and to one's responses to those surroundings (the premise of 'orange' and 'red' awareness levels is rooted in fear, either at the level of being startled, or at the level of fear for one's safety), gave participants a sense of control over their own sense of vulnerability, but a question I would ask is 'how does this change a body's habits?'

Recall earlier assertions in chapter two about women's tendencies to be hyperaware of their surroundings; their hearing and vision monitoring the landscape and those around them (Stanko 1988: 85), but also recall that what women are hyper-aware of will depend upon their background, upon wider social factors such as how they might be treated should they defend themselves, and the immediate surroundings.

For someone like Jen, such hyper-awareness tended to be influenced by a very abusive relationship she was attempting to leave: being aware of surroundings meant being wary of whose footsteps might be following her home, or being aware of whose phone number was showing up on her call display on her cell phone. All of this is to say that a given self-defence participant might have a great deal to worry about in their daily lives, many reasons to become nervous, depending on their surroundings or events taking 
place in their lives. This is why a colour-coding system for awareness-levels might offer at least the sense of control over one's own emotional responses to abuse and to leaving an abusive situation: where one's feelings create a storm within, colour-codes serve as a set of meanings agreed-upon within the context of self-defence. At the same time, they provide a tool for explaining to others who may not believe a survivor of abuse what is going on - they can say how, exactly, they are feeling and point to why.

\subsubsection{Coping with Vulnerability: Framing an Aggressor's Actions}

The colour-codes of awareness served as a framework in which to place events or feelings, so that, for example, a phone call did not have to mean automatically 'going into red' (i.e. assuming it was an abusive ex, or a stalker); it could mean 'going into yellow, then orange as one noticed the number, and not going into red unless a message being left was actually threatening. For Jen, this would carry through after the self-defence class was over:

Six months after the women's self-defence class had ended, I sat with Jen for a lengthy conversation over tea. I had spoken with her on several occasions on the margins of the class, as we set up the room beforehand, or in the few minutes afterward as we cleaned up. Now, we sat in a kitchen on a winter's afternoon, discussions of boundarymaintenance regularly interpellated by my cat jumping onto our laps and into the conversation.

"So how much do you remember from the class?" I sipped on my tea. Jen thought for a moment and leaned forward. "Hmm...Some basics I still remember... the three things? I can't remember how many... Think, yell, run, fight, tell... go for the eyes, fight like a cat-in-a-bag... The colour codes of awareness....but one thing I really appreciated was the part about trusting your instincts. Instinct is so not emphasized, even trivialized in our culture, but it's so important. It can be - should be - developed".

I nodded. "I don't know about you but for me it all seemed to fit together." Jen nodded, and as my cat interrupted the conversation again with a loud meow, she reached down to pet him. "It does, too. You know, when I started the class, and I mentioned that friend who would call constantly?"

"The one with the problems? He made you scared and angry when he'd call?" I asked. Jen nodded. "Yeah. He was my boyfriend at the time. I was trying to leave him, 
and I'd have panic attacks every time my phone rang... and after I left, he still would try to contact me, flood me with emails, call me, call my friends and family trying to find out where I was. I actually started using the colour codes whenever the phone would ring."

"I think in that situation, I'd use anything to not jump at every email or phone call," I said.

"Exactly. I'd ask myself - okay, who's calling? Him? Okay, is he actually threatening me in his message? Yes. I'll get a new number...leave him the old one...same with email and Facebook...He's left so many messages, some just to try to get at me, others..." She trailed off. Mac jumped onto the table and rubbed up against her face, purring loudly.

Jen petted Mac as he squeezed in between her and her tea. "We had pets at his place. I had a cat," she said softly, petting Mac and looking away from me. "I have three where I'm living now, but..."

Mac purred louder. I grabbed a tissue and handed it to her. "Whatever happened was not your fault."

"I've made my peace with it...I tried to rescue the cat, I got as far as getting her and making it out of the building..." Tears sprang to her eyes. Mac's body trembled from purring and he butted his head against her chin.

"He caught me and forced me to give the cat back. My own cat! He emailed me about it, saying it was my fault, and if anything bad happened it was my fault, and how if the cat starved, because he wasn't going to take care of it..." She shook her head.

"Whatever happened, I know he was trying to keep me in contact with him, trying to make me feel threatened and scared. That's when I just started applying the colour codes to his emails, to his messages, everything."

I handed her another tissue. "It's a lot less scary to look at."

Jen nodded. "Yeah... Because I can explain what he's doing with this language; 'I'm aware that he's messaged me, okay, he's trying to anger me, that message holds no substance, go back to my day' instead of going from 'having an okay day' to 'waking nightmare' with no...in-between, you know?" She paused, and Mac jumped down from the table.

She straightened up and sipped her tea. "The other things we learned, too, like in the Gavin De Becker book - even though I had issues with it for being so gendered towards just women and intimate-partner violence - the 'just break contact' part..."

"You don't respond, do you?" I asked.

She shook her head. "No. He messages me, and gets nothing back. I have no reason to talk to him."

A great deal more than the colour-codes came up in this conversation, and in fact much

of the three-hour conversation focused on our pets and how we could tell we were either in unhealthy or abusive living arrangements depending on how our pets responded to others. In fact this theme comes up in the Gavin De Becker book, mainly to reinforce a notion of intuition, or that understanding that comes from the body in a given social 
interaction. Jen, after leaving her boyfriend, used the colour codes of awareness from the women's class to manage her responses to her ex's attempts to antagonize and threaten her. She also used some of the lessons in the Gavin de Becker book to remind herself to detach - to not respond to her ex-boyfriend's threats, or appear to do anything. This cultivation of appearing to do nothing in response to threats, though not expanded on during the women's class, is actually a tactic used in martial arts (and in the advanced class): by managing one's own responses to aggression, one is in a better position to manage the aggressor and the situation as a whole. Detaching in this manner is a performance for the sake of the aggressor, whose behaviour receives less and less reward over time. It took Jen six months of ignoring her email, paying for a second phone number, and moving house to wait out her ex-boyfriend's attentions.

In a way, this enabling of new responses seems not so different from what Bernhard Waldenfels describes as breaking the purposive circle of communication, where the Other normally breaks one's own intentional circle (Waldenfels 2007: 25). In selfdefence, we learn to break the Other's (read as an aggressor's) intentional circle and recover our own as quickly as possible through use of techniques like the colour codes of awareness or the knowledge of how aggressors tend to behave. This also has the effect of allowing for the self-defender to respond to the demand of the Other in a way they might not have prior to training: the Other's threats no longer need appear as threats, but instead can appear as appeals for attention.

It strikes me that what Bernhard Waldenfels says about disruption of the everyday order of lived experience can apply to those who take self-defence training following traumatic experience: a gap opens between the Other's provocation and our response to that 
(Waldenfels 2007: 34), and if our repertoire of responses is limited, there seems little room for novelty or creativity. If, however, we have a deep awareness of our Selves, our environments, and can intuitively observe the Other, then it seems there is more room for what Waldenfels describes as creative response - even if we have a wide repertoire of potential ways to respond (avoidance, evasion, joking, fear, politesse), we can essentially make it up as we go along, such that our response "as a form of saying and doing begins elsewhere, without being grounded in a given sense or in existing rules" (ibid). Recalling that, for example, women tend to be socialized towards smooth social interaction over personal safety, we could say that effective self-defence comes from a willingness to break with 'the rules' - to choose not to respond, to analyze what an aggressor is doing, or to use physical force to escape.

\section{Chapter: Interruptions of Vulnerability}

\subsection{Taking Pain and Shedding Fear of It}

Self-defence training, insofar as it attempts to address people's vulnerability to violence, also attempts to address their vulnerability to both the fear of pain, and to pain itself. While fear of pain (whether emotional or physical) is not necessarily causally related to whether or not someone will defend themselves, it strikes me that such fear is one of the tools mobilized by aggressors - it certainly came up in the advanced class as one aspect of training requiring a great deal of attention, or at least training to work through pain, which we called target-hardening. Before I discuss this further, let us attend to pain itself.

Drew Leder characterizes pain through its "sensory intensification, its episodic temporality, and affective call, which establishes its peculiar hold upon our attention" 
(Leder 1990: 73), yet he also indicates that the importance of pain as an experience is only revealed when set within the broader context of meaning: Pain means intentional disruption, or disruption of our ability to function in the world as we were before the pain started. It also brings about spatio-temporal constriction, or intense focus on the body as object and pain as alien presence to the near exclusion of all else. These two experiential processes exert upon the body a telic demand, or demand for answers as to how to end the pain (ibid). While the experience of pain cannot actually unmake our lived, interrelational world, it threatens to by forcing our attention back towards the body and it is this structure of pain that self-defence training aims to interrupt, if only by ignoring pain's call to our attention. This has some potential for re-habituating the ways in which a survivor of abuse relates to the world if we consider the structure of pain through the lens of Collins' notions of violence and abuse. Recall Collins' assertion that the victim's cringing makes aggressors respond with disgust and anger that fuels their violence. If the victim is forced to attend to their pain when struck, to the exclusion of everything else (as in Leder 1990: 74-76), it makes it easier for an aggressor to take emotional energy from them - they are so 'wrapped up in their pain' - a fundamental structure of bodily experience - that they do not have the energy to defend themselves. In self-defence, participants attempt to learn to interrupt their own bodily tendencies to attend to pain, if only by deliberately ignoring it long enough to focus on defending themselves. It also strikes me that by learning to take pain in this way, whether or not participants lessen pain at all, they lessen the fear of pain through exposure to it, even though the novelty of pain never goes away - a painful experience hurts, even if a body is used to hurting, even if one has trained at length to ignore it (see Leder 1990: 73). 
By accustoming the body to pain, and by teaching participants not to fear the experience of pain, self-defence training does offer participants a way to interrupt an aggressor's use of pain, or fear of it, and thereby stop an attack. If participants can become better able to take pain and push past it in order to defend themselves, they can interrupt the violent situational process, and gain some leverage over the situation. The process of learning how to take and not fear pain is what is referred to in training as 'target hardening' - in essence, training the body to take physical pain, but also training the totality of the person - not just that their body can take pain, but that they realize it, too - 'I can take pain. This is a surface bruise from being pinched; I am not damaged.'

In the advanced class, we signed a waiver on our first night, stating that the dojo would not be legally liable should we suffer a certain level of personal injury during training. Given the pace of the class, there was no time for being unable to take pain - we worked through bruises, joint-manipulations and locks, and by the time each 90 minute session was over, we left the building with a mixture of the kind of high that comes from intense physical activity, and aches that would linger for days while the bruises healed over.

By contrast, in the women's class we did very little physical target-hardening. Rather, we focused on learning "to dish out" pain - how to do it, where on the body to apply pain, and how much force would be required to stop an attacker. However, the main focus in that class was what could be thought of as emotional target-hardening, or learning to take the insults that come when one stands up for oneself with words alone. Having us role-play as aggressors helped us try to 'get in the aggressor's head' as we progressed from week to week, and also served as the bulk of 'emotional target- 
hardening', in which we took up the perspective of an aggressor who 'used ploys to get our attention and keep us in the interaction' such as 'do you have the time? Can you help me? Let's talk. Can you help me? Why won't you pay attention to me? Why are you such a bitch? Why don't you ever...?' (Sensei Tasha, in-class discussion, July 16, 2012). This use of perspective-taking was meant to help us understand, as Sensei Tasha put it, "what keeps the attack ticking over in his head", but also to understand that these 'ploys' were just that - "ploys, and not genuine, caring interaction. If they were, they would not escalate to name-calling or emotional manipulation, would they?" (Renshi Diane, in-class discussion, July 16, 2012). With this in mind, we used the colour-codes of awareness as a first indicator that an aggressor's behaviour was worth a closer look:

Sensei Tasha asked, "What triggers you into going into orange, or maybe what 'creeps you out'?"

Is it that they stare?

- Do they sit too close or stand too close?

- Do they touch us without permission?

- Do they smile at inappropriate times?

- Do they laugh at inappropriate times, and do so to make you feel uncomfortable?

- Do they offer un-requested help, only to actually hinder the process of what it is we were doing?

"These are all valid reasons for going into orange. And when you go into orange, when you're feeling creeped out by this person - let's get into their head for a minute. What do they or don't they want?" Sensei Tasha asked.

"What is the attacker thinking?"

- He wants a compliant victim (oblivious, too weakened to resist)

- He wants to time things right (hands full, too tired or drunk to resist, family or children nearby whom she doesn't want to disturb or frighten)

- He wants a victim to question herself so it makes his life easy ('hey I was just asking the time, only trying to help, just making conversation')

"Right now, we're not worried about why he wants to attack, we're worried about what keeps the potential attack ticking over in his head. He does not want a noncompliant victim". A noncompliant victim would ask him to back off, decline his request, and give stronger refusals each time; or finally respond with force if he did not back off.

Sensei Tasha paused. "If you don't comply - he might call you names. Some of them pretty hurtful. But if the end result is he leaves you alone, that's okay. Nothing wrong with being called a bitch, if he leaves," she paused again. "Now if he doesn't, 
that's when we might need to really respond, and get out of there, and get to safety," she shrugged.

Combining the identification of these behaviours together with trusting our instincts - by making deliberate use of the body's tendency to respond to the world and others - about a potentially threatening situation and then responding took more than the eight weeks of the course to perfect, depending upon situation.

We were being asked to codify our responses to particular behaviours in part to talk about them with others, but also in part to connect more quickly between the experience of a given behaviour ('do they stare too long?') and the feelings that behaviour brings about. In the context of the women's class, we gear into the world deliberately and make use of what would, I think, otherwise be a subconscious 'motor intentionality' of extending into the world and receiving responses back - for example, hearing a harsh word, and one's body naturally responding by recoiling. Where at first, we tended to 'pull' our techniques in more physically-oriented practice, and to break character in the situational role-play, over the eight weeks, we began to be able to push boundaries back and forth. In different role-play scenarios, participants tended to rely on a combination of socialization and physical techniques learned in-class. One evening with five of us present, we role-played our boundaries being transgressed or being physically attacked:

\section{By a co-worker or boss}

When Claudette paired up with me and played as the would-be 'victim', she spun around, glaring at me before I could put a hand on her and said, "Don't touch unless you want to speak to the Labour Board." I stared for a moment and asked how she had learned to do that, because I had never been able to stop anyone from sneaking up on me or making crude comments in past jobs. "Just good hearing, I guess. You learn what they sound like, catch 'em before they can lay a hand on you, or walk up to you, you stare 'em down... but they have to know you can back it up." 
Claudette had experienced some sexual harassment in the workplace, but over the years, had learned not only which administrative bodies could be used to make a complaint, but also how to make an effective threat - she said that threats worked best when they were already underway, when said so forcefully they surprised a would-be attacker, or when they could be 'backed up', usually by having allies, whether among co-workers or in management. Her strategy was not unlike having a language with which to talk to law enforcement or a judge as would be seen in the advanced class - protection of the body in the immediate situation and protection of the socio-legal person, albeit by threatening the professional identity of an aggressor.

\section{By a date}

I paired up with Ella and made a face at our scenario. "Who wants to be the aggressor? We're on a date..." Ella shrugged and grinned. "I'll go." She walked around to an empty chair beside me and sat down. "Hey. Whaddaya say we get outta here? This movie sucks. I got a better idea... Something fun, y'know?" I stared. She moved closer and put a hand on my knee. "I'm not hearing-" "Not really..." "C'mon..." she wheedled. I grabbed her thumb and pried her hand away. "No." "I know you don't mean that! C'mon." She grabbed my hand with her free hand and began to pull me up out of the seat. "I really just want to watch the movie..." I let her pull me up and then stepped in. My free hand went to her face, and I pressed against her eye. She let go of my hand and tried to put hers up to get in my way. "You bitch! I was only trying to have a little fun!" She insisted. "No..." I pressed her eye further until her head tilted back and she took a step away.

Despite this scenario being practiced halfway through the course, I still found myself relying on a particular form of socialization for my responses: weak refusals and complying with an aggressor until an opportunity to physically disengage from a situation arose. When Ella and I switched, she responded with a firm 'no' much more quickly and when I 'threatened to break off the relationship', she shrugged and walked away. 'So you don't even love me anymore?" I cried out mockingly. Ella ignored me and walked to the other end of the boardroom, staying there until I got up and got back into my own chair. For Ella, getting up and walking away at the first sign of trouble tended to be her 
favoured response - she explained that the faster she removed herself from a situation, the less likely she was to hear whatever things an aggressor might say to keep her in the interaction. "Like if he calls you names?" I asked. "Worse," she replied. "Like what you did there with the 'so you don't even love me?' part? I had an ex who did that all the time...made them hurting me about their feelings." She shook her head.

\subsection{Dishing Out Pain: From Aversion to 'Do What You Have To'}

It strikes me that part of women's socialization as caregivers and nurturers involves, in addition to prioritizing smooth social interaction, prioritizing caring for the pain of others. Part of 'caring' socialization is directed towards empathizing with, and ameliorating, the pain of others, even aggressors (if only in the hopes of avoiding further aggression). In self-defence classes, women are taught to push aside this tendency to ameliorate the pain of their attackers. Before they can reach this point, however, they must change the way they view and act in their bodies: from a project for continuous aesthetic improvement, to a potential weapon for self-defence, to seeing their bodies not as objects at all, but as the foundation of their very selves, equipped with dangerous defences.

Mary Stewart asserts that women are "not accustomed to viewing their bodies as weapons...that they have a difficult time even making a fist or hitting another person with any accuracy or real vigour, and that when they harden their bodies through exercise,

they do not see themselves as developing a machine for aggression, but defence" (Stewart 2002: 169). It strikes me that Stewart has actually described developing one's body as a weapon, even if it is a defensive one, but this point aside, women may very well be accustomed to developing the human body as a defensive weapon, they just might not be 
accustomed to using it that way when the need arises, specifically because they are vulnerable to violence from those closest to them - and when they are not thinking about the necessity for defending themselves. Stewart's argument is not without merit: for a woman who has not trained extensively - and recently - to withstand her own pain, or to be willing to dish out pain to others, dealing back and forth in pain could be very difficult. When I asked Sensei Tasha what brought her to take and teach self-defence, she said:

"I went to my first women's martial arts conference, and the women there introduced me to the framework... showed the internal socialization.... and it was one of the nights I was staying there, sitting in my room in the hotel, that I realized I had been through a significant sexual assault."

I nodded. "The family friend you told us about in class?" She nodded. "It was. And you know, I figured if I, having had martial arts and self-defence training, didn't know what to do when it happened, there was a good bet other women wouldn't know what to do." 
Sensei Tasha's point was that without some training explicitly in managing one's responses to pain, to threatening situations, and even to one's empathetic tendencies, it would be very easy for an aggressor to overpower a woman; and more so without training in seeing oneself as being equipped with a myriad of defences. Even the "perspectivetaking' exercises taken up in the women's classes could be seen as trying to accomplish this goal: making use of empathy in a new way - and training participants to distinguish between empathy (as perspective-taking) and sympathy (as vulnerability in the form of feeling sorry for an aggressor's plight). This, finally, is what emotional target-hardening looks like, and whether it is more difficult than the physical variety, it is at least somewhat more difficult for participants to assess within themselves - how does one know he or she has developed the emotional defences alongside the physical ones?

In class, Sensei Tasha had also shared with us a story of a former student of hers, a young woman who, while walking for groceries, found herself surrounded by a group of young men.

"Women are very creative when it comes to protecting themselves. A former student of mine was out walking here in the city when a group of guys surrounded her and started threatening to rape her, saying explicitly the things they were going to do to her. She responded: "REALLY?" And started unbuttoning her jeans, looking overly excited at one of the guys. The group didn't know what to do about this, so they backed off. Why? Because rape is about power, and she took their power away."

Whether women are accustomed to seeing their bodies as weapons or not, it strikes me that self-defence training is intended to inculcate participants in that sense of body-asweapon/being-as-capable. This came out often during the advanced class, whenever Sensei Ray would call up one of the female Senseis to demonstrate a move or set of moves.

"Ladies...” Sensei Ray looked around at the women in the class. "...I bet you've seen this 
one hundreds of times. Guy comes up at the bar, he's bought you a drink, figures you owe him something - gets a little handsy-" Sensei Samantha, standing nearby him at the front of the dojo, turned to face him. He stepped up to her and slung his arm around her shoulders, closing into her space.

"C'mere darlin', c'mon I bought ya that drink!" Sensei Samantha grabbed his hand away from her shoulder by the thumb and locked the joint with one hand, pinching under his arm with the other. He jumped away from her, but not before she pinched even harder, leaving a nasty welt. "Ouch! Hey!” Sensei Ray rubbed his arm and grinned widely at us. "Now what am I gonna say to the bouncer? Oh, she grabbed my thumb and she pinched me? If it's a police officer and I tell 'em that, at best they're gonna roll their eyes, at worst, well now-I'm- wasting police time, right?"

Sensei Samantha responded as one accustomed to seeing her body as a weapon for defense and attack, as well as one who could endure pain long enough to respond to aggression in kind. Then again the situation of being in the dojo, training specifically for physical confrontations, might have made it easier for Sensei Samantha to respond quickly and effectively to Sensei Ray's attack. Aggressors 'out there' beyond the walls of the training hall wait until their target is not only unable (ill, stressed, not easily able to defend themselves), but giving off signals that they are unwilling to defend themselves vigorously, as mentioned earlier in the discussion of the 'assertiveness' exercise in the women's class.

Early on in Sensei Tasha's class, we worked on learning to apply pain to others, and to trust that we weren't going to cause them permanent damage by doing so:

"I'm going to show you how to stop an attacker right in the middle of their attack. Renshi Sam's going to attack me," Sam stepped up to the centre and put her hands around Sensei Tasha's throat. "Two things - I'm going to track up her arm," Tasha's hand went over Sam's arm, over her shoulder, and up to her face. "And then lightly press into her eye." She cupped Sam's face and pressed into her eye with her thumb. Sam's hands came away from her neck and her face moved away from the source of pressure.

"You don't need much, which is why it's my favourite place to go if somebody's attacking me - straight for their eyes. I'm going to have you partner up with an instructor for this one." Sarah and I got Renshi Diane, who first had us try the technique on her. "Don't worry about tracking, we just want to get the eyes part down," she said. Sarah went first, pressing with her thumb right into Diane's eye so her head moved back. "Good." I tried, pressing my thumb too close to the edge of her eye socket. "Nope. Too 
soft." Did she want me to press harder? "That too, but get right into the centre of the eye." The second try was in the right area, but still too soft. "Make my head move away." I pressed again, the centre of the eye, and Diane moved her head back. "There you go! Don't be shy!" We did the exercise again with Diane putting her hands at our throats. Sarah tracked up over her arm and pressed a thumb into Diane's eye. I did the same but as my thumb went to Diane's eye, again I was being too soft. Diane pressed her thumbs down onto my clavicle and I found the centre of her eye and pressed. Her hands left my throat. "Better! Don't worry about hurting me; I can take a little pain. This is about getting you out of trouble," she said.

I blushed and glanced around the room - Leah, holding her arms close to her body, reached hesitantly and lightly pressed her thumb into Renshi Sam's eye; Jen was laughing somewhere behind me, Carmen and Ella were practising tracking and going for the eyes on each other while Tasha watched. "I thought I was less shy than that," I said apologetically. "Don't apologize," said Diane. "It's your first day!" "But I used to do Taekwondo and Karate," I said, frowning. "I should -" Diane patted me on the shoulder. "It's still your first day," she grinned.

This training gave participants the opportunity to experience both dealing and receiving the kind of pain we would need to become familiar with - meaning that none of us in the group would be asked to apply more force than we were ready to; but we would be asked to understand that the force we did apply in the class was not enough to damage our training partners. This opened up the door for being able to increase the pain we were willing to cause, depending on the situation being acted out, or depending on whether our partners indicated that we were not working effectively to stop an attack. However, while it did open the doors to these possibilities, I noticed that in the women's class, participants 'pulled' their techniques, that is, avoided causing partners pain. In the advanced class, as noted previously when it came to understanding violence and acting as an agent capable of responding to violence quickly and effectively, there was little room for not having an embodied understanding that one could take and deal out pain without serious consequence:

The next-to-last session of the advanced class was rough, but didn't feel that way. How to describe? From evading bear-hugs by stomping on insteps to pinching arms and jabbing 
throats to escape chokeholds, we moved on to fighting with chairs - one partner sitting in the chair, and the other person trying to get them out of the chair.

I worked with Senpai Tammy and as she struggled to pull me off the chair, I found myself unable to think of anything we had learned as I grabbed a hand by the thumb to peel it off me and stomped at her feet whenever they came near. She didn't seem to mindthe point was to get her off of me, and not stop to think about it. She grabbed me in a headlock.

"What have you got?" Senpai Tammy asked brusquely. I reached up behind me and grabbed her ponytail, pulling her close enough for me to 'track' my fingers up her neck to her face with my free hand. I pressed into her eye with my thumb as I began to turn and get up. She moved slightly and put her hands on my shoulders, pushing me back down. "Good! What else? What if you can't get my face?" She stood up a bit. I reached behind me and gave her inner thigh a pinch, twisting her skin through her jeans in my fingers as I pulled away. She let go and jumped back. 
We can see a difference in responses depending on setting - the advanced self-defence class, despite being marketed as a class that could be taken with little exposure to such training, worked best for those of us who already had experience with combat sports, or who worked in fields which addressed violence and all its situational aspects - the need for controlled affective performance: the need to apply empathy appropriately (remembering that an attacker is an attacker, not a person to nurture); and to learn to tolerate and apply pain to others.

The women's class tended to function in ways closer to a support group - getting participants used to these ideas as ideas, with some practical application, but not necessarily engaging participants in doing these things actively.

With this said, however, both classes still aimed to help participants frame violence and vulnerability, understand the threats they were most likely to face, and then begin responding.

\subsection{Managing Aggression and its Impressions}

If self-defence for women is about learning to use aggression judiciously, what about self-defence for both sexes - and what would be the implication for men?

Sensei Ray opened the class one night, not with a military-style drill, but with a story. He paced the room while we stood in our line, applying hand sanitizer and rubbing his hands back and forth. "Funny thing happened this morning. I was patrolling all night long in this factory, and I know the boss pretty well. I'm finishing my rounds, when outta the boss's office comes this young lady wrapped up in a blanket! Now, the place was quiet all night, and I'm thinking 'how'd she get in?' So the first thing I said to her was - 'what's up?'” He grinned at the class. "Turned out she was the boss's daughter and she needed to crash overnight. Her parents were out of town, she was here for a school visit, and parent's house was too far away. A quick call to her parents to check her story - I didn't freak out, didn't get fazed, just smiled and started with 'what's up?' As you should, if 
you're on duty or even off-duty, and just checking a place out. Could be your place. Could be your car, and someone's approached you. Just make eye contact and ask what's up". He rubbed his hands together again.

Recalling Stanko's and even Collins' work on violence, and turning one's attention to masculinity, it strikes me that there is a social expectation that men know what to do in potentially threatening situations: that is, they are socialized to respond with aggression during confrontation - yet they are not taught explicitly how to defuse confrontations well in advance of such escalations. Sensei Ray emphasized de-fusion tactics to some degree, although mainly in terms of managing aggression and its appearances to both potential attackers and to bystanders, as somewhat of a response to the use of aggressive displays as de-fusion tactic. Those who do not engage in such displays of aggression, and who are subject to bullying and abuse from fellow boys growing up, and fellow men as adults, are given some new possibilities for responding in such circumstances: for seeing their own tendencies not as 'weakness' or a lacking in their performance of masculinity but as a strategic tool for interaction.

It strikes me that the practice of aggression/impression-management channels a notion from Erving Goffman's dramaturgical framework, but not quite 'impressionmanagement' itself. Erving Goffman says "regardless of the particular objective which the individual has in mind...it will be in his interests to control the conduct of the others, especially their responsive treatment of him" (1959: 3-4). By managing one's aggression, and managing the impression given off of that aggression in a conflict situation, participants in the self-defence classes (particularly the advanced class) are learning to subtly exert some control over others' responses to them. 
By doing this, they can potentially regain control over the attacker in the situation (particularly if the aggressor's violence is triggered by a display of relative helplessness), but also control of bystanders' responses. The intent behind aggression/impressionmanagement is to make clear who the aggressor is in a conflict situation.

Even though the dynamic of aggression and impressions given off never came up in the women's class we attended, Claudette mentioned offhand in a follow-up interview that she felt a self-defence class would be good for men to take, and as we will see later on, some issues of performativity did come up in the women's class - as far as the impressions of confidence or lack thereof were concerned.

"It's a real eye-opener. I even love the Gavin de Becker book that we got, because it does talk about what both men and women have to go through. A class like this is a good one, even for guys - they tend to be a bit docile...naive. A class like this can help them." I raised my eyebrows as I wrote furiously. "Guys? Docile?" Claudette shrugged and smiled. "Yeah, I think they're pretty docile for the most part. I think it's why they freak out when something happens, and I think in a class like the one we took, they learn assertiveness, and learn to listen to their instinct, that's a big one, and pay attention to what's around them."

Claudette's description surprised me at the time, especially given Sensei Ray's ongoing emphases on aggression-impression-management in his class, and Sensei Tasha's own references to keeping young men safe, from getting into fights, during our after-class conversations. However, what I had not understood in that conversation was two-fold: most people - not just men - outside of professions that address violence directly (such as policing or military) are not necessarily inclined to aggression or violence. Claudette was talking about the men she knew and saw every day - men who were not in combat sports, or in security or policing professions, or who had not learned to affect aggressive capability in a particular way.

With this notion in mind of aggression and affective performance, we are now in 
a position to understand both Claudette's assertion that men could do well with such training, and to understand self-defence as affect-management. In Sensei Ray's class we were taught to actively manage our own responses during a confrontation in order to either: defuse it and return to smooth social interaction, or to escape the situation.

In short, and using words like 'engage, disengage, tactic, strategy', the advanced class challenged the idea of affecting aggressive capability, and encouraged participants to work towards escaping a threatening situation: two things not normally associated with traditional (western) masculinity. The cultural ideals are to 'not back down', to confront, and 'show them who's boss'. In Sensei Ray's class, this was not what we were to do, and further, any uses of physical aggression were to be with the intent of defusing the situation as quickly as practical. Further, those same uses of force were not to appear forceful or aggressive:

I paired up with Renshi Marta to practice a finger joint manipulation, but no amount of gripping, twisting, or bending her index and middle fingers could make her respond or move in the quick, reflexive way Sensei Ray had showed us at the beginning of class: ideally as soon as I put pressure on her joints she should have sprung to her tiptoes and been ready to move in whichever direction I 'steered'her by means of pressure on the joint. Sensei Bruce came over and stopped us. "Whoa, way too hard. You know what would happen if I did that to a civilian on the job?" He looked at me. "I'd lose my job, right? So I'd never do -that-"

I blushed. "Sorry! Sorry, Marta." Renshi Marta pooh-poohed the intervention. "It's okay! She's just stretching the joints a lot. I don't quite feel it, really."

Sensei Bruce raised his hands as if giving himself up. "That's okay, but see, that's the problem - not everybody responds the same way, so Marion, I want you to go slow." He folded his hands in front of him. I gripped Renshi Marta's fingers again and tried to tilt them back towards her wrist. "Nope, you're still bending too hard, and holding too soft your hand needs to keep her fingers from moving." He paused as I wrapped my hand around her fingers again. "Imagine you're holding a joystick," Sensei Bruce said. I moved my hand up from Renshi Marta's knuckles, squeezed her fingers, and gave the knuckle joints a slight bend right, then left. Each time, she moved in the direction of the pressure I exerted on her. 
Sensei Bruce, though I had not recognized it at the time, was demonstrating not just knowledge of how pain or injury on the body works, and how this could be generalized from specific techniques. One of the first things he said to me was that if he were to try and stretch or pull hard at someone as I had been, he would lose his job - in short, he was pointing out that my technique was - and looked - aggressive.

Aggression/impression-management, along with awareness skills, permeated the entire course, but this skill seems not quite the kind that can be taken up via learning specific techniques - even though the utility stance we learned and repeated each week was intended to position us into doing just that: performing a kind of aggression/impression-management by keeping our hands where people could see them, keeping the hands open or slightly folded or clasped in front of us.

Managing expressions of aggression meant understanding how the techniques we practiced could injure a body, applying only just enough speed and force to get a response out of a practice partner, and also managing the appearance of our use of force. Managing the impression meant understanding how supplicating body language could be used to both deceive a would-be aggressor into thinking they had an easy mark, and to ensure some legal protection, should a confrontation be caught on camera. As mentioned in the previous chapter, the advanced self-defence class tended to be about both the defence of the lived body in immediate, escalated conflict situations, and about defending the socio-legal person, first by performance in those immediate situations, and then by having a language borrowed from the security and policing professions to talk about how the situation escalated in the first place (and what the practitioner did to de-escalate it). In such cases, the self-defender could point to how non-aggressive their responses were, 
could indicate that they tried to de-escalate the situation, and could highlight the selfdefence aspects of their actions if they found themselves before law enforcement.

In those instances of being directed to slow down while practicing jointmanipulations or body-leverages, and in the stories shared by Sensei Ray, what was being inculcated was a form of aggression-management meant for escalated conflicts. Recall Collins' suggestions that signals of weakness such as cringing or flinching tend to 'draw' an aggressor into violence (Collins 2008: 135-150). For those learning to manage both expressions of aggression through their use of force, and the impressions of aggression given off to others in such an interaction, the lesson is two-fold: both in terms of appearing in control over oneself should law-enforcement ask questions, and also in 'faking out' the aggressor and triggering their violence, so as to encourage a response from them. When Sensei Ray would describe this as interrupting the aggressor's 'loop', this notion of taking control over the situation, and following their escalation to a point where the self-defender could respond quickly and then get to safety may have been what he meant.

What was being inculcated here was a kind of martial tactic - and an advanced one that would require more than 12 weeks' worth of practice once per week: It combined learning not to flinch in the face of aggression (being able to take pain/fear of pain), unless deliberately with being able to attend to an interaction, to one's own responses to confrontational tension, and to respond to that situation, using force if necessary, instead of 'riding the violent situation' in the way Collins suggests violent situations happen, and finally being able to break away and get to safety. Such skills as these come from repetition of their component-movements, but putting them together in 
new ways to respond to a given situation, particularly in its emotive/affective aspects, seems to come from the participant's own body-schema.

While 'aggression/impression-management' was taught in Sensei Tasha's class, it was not the skill emphasized most often. In Sensei Tasha's class, we were taught to interrupt a violent incident about to happen to us, at the expense of smooth social interaction, to yell loudly, and to affect aggressive capability to some degree, provided we were prepared to use force.

\subsection{Where does Vulnerability Come From?}

It strikes me that for both genders, it is their traditional performance that creates their vulnerabilities, and self-defence practice offers the potential to let participants see their own socialization as a process, borne through a lifetime of experiences. In the men who took the advanced class, it may well be that a sense of invulnerability, or at least its practiced affect, creates the conditions for panic during confrontation, in part because of the social (or, for practitioners in the security-related professions, occupational) assumption that they would know what to do in a potentially violent situation. That moment of panic potentially creates vulnerability for men who find themselves in a violent situation; both the vulnerability of being attacked bringing about the reality that they are not as invulnerable as they think they are, and the 'vulnerability' of attacking someone in a moment of forward-panic. Sensei Ray often cautioned his students, men and women alike, to keep control over their responses during threatening situations, although he did not use the language of vulnerability. Instead, he tended to caution students not to "get caught looking stupid with your hands up like this [making fists], or 
caught wailing on somebody, because you never know who's got a phone camera”. At the same time, however, the language of 'patient, vulnerable' women did find its way into the lessons in the advanced classes, whenever Sensei Ray mentioned that "you guys - you, guys - could learn from the females in the room, some patience when you're out there. Just don't get walked on though. And don't walk on the ladies".

In the women's class, the instructors and students discussed an ongoing vulnerability stemming from an embodied, socialized unwillingness to fight to protect oneself, an unwillingness trained into social norms and bodily comportment. We saw this early on in the class during one of our group discussions. It was a small group, and Sensei Tasha opened the class by handing out a sheet of paper with a set of questions on it and had the group break up into pairs to answer them, and then return to the group to discuss the questions and answers in greater detail. The paired-off discussions were fairly short, and when we came back into a group, I made note of everybody's answers.

- Observe your body language when you sit, stand, and move. Are your arms free or do you tend to keep your hands in your pockets, folded in front of you or behind your back? Is your stance firm and balanced?

Of the three students present, all of us agreed we tended to move freely and stand steadily.

- Is your head up or do you look down, avoiding eye contact? Do you stand tall or slump your shoulders, 'cave in'? Can you identify times when you are likely to take up little space? These are times you are more vulnerable to harassment or attack.

All three of us could identify times they had been likely to take up less space, and this question spawned many stories from students and instructors alike. Jen described being harassed on public transit while slouched over from sickness; Ella recalled an exboyfriend pressuring her for a one-night stand 'because she looked lonely. 'She had just lost a family member. I described being harassed by a former friend who was 'concerned for my well-being' because I didn't go out drinking with her. 


\section{- Do you speak so others can hear you? If introducing yourself in a group, can others hear your name clearly?}

Almost everybody in the room said yes to this except Renshi Diane - she had worked for a long time to work on being clearly heard.

\section{- Do you tend to apologize for yourself or your opinions?}

The three students said yes, but when 3/4 instructors said they still tended to do this, the students stared at them. Renshi Abby described how she tended to qualify her speech at work, Renshi Diane said she didn't apologize per se, but that she still says "in my personal opinion", even when speaking for her company. Sensei Tasha said she too found it easier sometimes to over-personalize her views 'oh it's just my opinion' and apologize for them.

\section{- Do you avoid conflict because of fear of disapproval or a need to maintain 'peace at all costs'?}

All of the students said yes to this; Jen would later tell me that when she had said 'yes' to this question, she was thinking of her boyfriend, who she was trying to leave. Ella had said yes, "not because I have to, it's just easier to get along". I had laughed mirthlessly and joked about having 'the magical power to stop any fight in my parents' household' while growing up.

\section{- Do you tend to immediately go to aggression - pointing fingers, yelling, using sarcasm, put-downs, threats, or physical violence?}

All three of the students said no... although nobody asked if anybody went to aggression after pleading or reasoning with someone who was not respecting boundaries. Had that question been asked, I would have answered yes.

\section{- Note situations that are most challenging for you - strangers, authority figures, in your family, in the presence of a group of friends}

For each student, the challenges were different. Ella said her parents posed the most challenge. Jen said her boyfriend. I said 'friends.'

Something could be said here of what Erving Goffman terms 'expressions given' and 'expressions given off' (1959). Holding the limbs close to the body and focusing one's attention inward might be a way of expressing that one is not interested in the other's advances or attentions. However, these also give aggressors the impression that 
one's energies are literally directed inward - in other words, not outwards in a way that would challenge an aggressor. During the exercise, Sensei Tasha did point out that those times when we took up less space or apologized for ourselves, we were much more likely to be attacked.

At the time of writing down everybody's responses to the questions, I paid attention to the answers without quite understanding their significance, given that the class was already small, that on the evening in question, we were very few, and further, that those of us who were in class, sharing answers that evening, have all survived varying levels of harassment or abuse.

This is not to say that abuse survivors have a set of experiences so far out of the norm that those experiences are not worth discussing. It is to say, however, that abusive dynamics tend to highlight the extremes of how social norms such as gender and its performances are sanctioned or enforced.

I have mentioned Sylvia Burrows' assertions that over a lifetime, women's socialization creates "a network of behaviours" that signal women's "inability or unwillingness...to defend their bodily integrity" (2008: 129). The assertiveness exercise highlighted the network of behaviours that signalled our own 'unwillingness to defend ourselves' at times: apologizing for ourselves or our opinions, holding our limbs close to our bodies, affecting caved-in posture (shoulders slumped, hunched over, head down). Such behaviours could be seen as the sort of repetitious acts that Judith Butler says make gender (Butler 1988:525), but what of gender performances as carried out by women who have been abused? Are they 'hyper-normal' if we follow Burrows' reasoning, or is it perhaps more reflective of lived reality to say that years of repetitious acts - apologizing 
for oneself or avoiding conflict (or in my case, eventually lashing out aggressively) make victims (who are not necessarily representative of 'women' in general, but rather, women with particular sorts of experiences) in need of retraining their responses and their awareness of what their body language 'means' to aggressors, particularly on days when they are stressed out?

Emotional vulnerability, particularly in terms of control of one's own responses or having one's responses controlled by others, is something we spoke of a great deal in the women's course, particularly how women are socialized to be sociable, nice, caring - and how aggressors use that socialization to their advantage. Addressing this vulnerability requires ongoing practice from the would-be self-defender, as its premise is learning to prioritize personal safety well above smooth social interaction, and learning to reconnect with the emotions that allow for such defences: reconnecting with anger, or even De Becker's 'true fear' (that is, the fight/flight response, as opposed to worry or anxiety) and using these emotional resources to defend oneself or escape a situation, rather than stopping and engaging in self-defeating thoughts ('oh I'm just being silly, it's just a compliment, I shouldn't be rude'). This goes against years of socialization, and can be more difficult to master than interrupting physical vulnerability through training, because one needs to develop the belief that they are worth defending in the first place. This emotional capacity feeds so many of the habits that self-defence training aims to inculcate. I will return to this problem with self-defence training, habituation, and martial arts later on, when I discuss the effectiveness of self-defence training, given the length of time required to re-habituate a body's set of responses, even within a limited range, such as responses to threat, or potential/ongoing violence. 
Emotional vulnerability was also addressed in the advanced course, though it was vulnerability of a different kind - where in the women's course, vulnerability was framed in terms of years of socialization not to fight back, in the advanced class, the vulnerability was framed as being borne out of the immediate situation. The women in the advanced class may have been working on socialized forms of vulnerability as part of ongoing emotional healing, but this was never discussed or brought up in casual conversation. As for the men, the notion of situation-bound vulnerability seemed to be centered on both the tendency to panic in a confrontation, and for their own socialization: boys tend to grow up being socialized to fight back when bullied or harassed, with the expectation being that they will 'know' what to do in a confrontation as they grow up. At the same time, men live in a world where stranger-danger is a legitimate concern. In Canada they are more likely to be robbed than women, and they are at greater risk of homicide (Sinha 2013: 12). I noted earlier that self-defence and 'safety' discourse tends to ignore this lived reality, instead emphasizing the 'stranger-danger' narratives for women, ignoring their risks of being victimized by people with whom they were most familiar. It strikes me that where men are concerned, the discourse and socialization operate in such a way that unless they are in professions where violence is well-understood, they do not know their own risks, which creates a hidden vulnerability that does not turn up until they find themselves in a confrontation or potentially threatening situation.

\subsection{How to De-Escalate a Situation in order to Escape It}


The women's class tended to focus less on tactical uses of aggression/impressionmanagement, and more on actually de-escalating conflicts before they could reach the point where such aggression-management skills would be necessary:

We were sitting in a circle on the last day of the summer class. Sensei Tasha started the session with the thought that "one of the things we learn in self-defence is that it doesn't always look like self-defence. Sometimes it looks like de-escalating a situation before it turns into an altercation. What are some of the ways you might de-escalate a situation?"

Sarah piped up, "speak softer so they're forced to quiet down". Carmen said "apologize, even if it isn't your fault". Jen said "agree with the person, like 'yeah, I totally understand, this situation sucks' and turn the other person's attention to the wider situation as a whole".

We practiced some of this. I paired up with Claudette, and we role-played as if we had bumped into each other in a bar. "You just soaked my dress!" Claudette exclaimed. "I am so sorry! I'll pay for the dry cleaning," I offered. "This is my best dress, I can't believe this," she growled. "I'm sorry, that was so clumsy of me!" I put my hands up and clasped them in front of me.

It seemed a little strange to be roleplaying acquiescence, given that women are already socialized to do so, and that acquiescent behaviours are already associated with unsuccessfully thwarting aggressors. Perhaps from a wider perspective - 'how to deescalate a situation with strangers', 'how to understand the signals given off by aggressors' - we can see what the women's class was trying to address: multiple types of situations which could escalate into violence. Sensei Tasha made it clear that the purpose of self-defence is safety, and that sometimes to preserve our safety, we may have to comply with people, even in more escalated situations. 
I stared at Sensei Tasha. "What about in cases of sexual harassment or assault?

Shouldn't we try to fight back? What if they're stalking you and they just won't quit, no matter how many times you agree to what they ask for?"

The other two class participants in the room, Jen and Claudette, looked at me. Sensei Tasha paused. "Sometimes it's not safe to fight back immediately. And if you have to wait the guy out until you have the first opportunity to escape the situation-you did what you had to, to survive. That's self-defence," she said softly.

In my experience, and in the experience of other participants (notably Jen), an aggressor will find ways to continue escalating, in spite of one's attempts to calm them. At that point, the tactic of acquiescence becomes a performance, not for bystanders as in the body-language taught in the advanced class, but for oneself, a way of reminding oneself that they did everything they could to de-escalate the situation before escaping or responding to it. In Jen's case, this was a deliberate survival strategy reinforced by the material covered in the women's class. In mine, it was one I had perfected over years, with one critical difference: in self-defence, the goal is to escape the situation. My goal had, for most of my life, been survival-by-acquiescence without the option of escaping, and sometimes survival-by-lashing-out in the hopes of frightening off an aggressor. Jen's goal was more immediate - to leave an abuser who used physical violence against herself and her pet to keep her under his control, and to stay safe in the process of leaving. Within six months of finishing the women's class, Jen had left her abuser by taking up both a renewed sense of self-worth, and a sense that it was possible to protect herself and remove herself from a potentially dangerous situation, by using the techniques we learned together. At the time we spoke, she had gone through a significant depression, and she made the point that leaving had been as dangerous as it had ultimately been better for her.

\section{Chapter: Conclusion}




\subsection{Conclusion}

I began this project with a view to examining self-defence as a response to violence against women, and through many iterations, found a niche in examining vulnerability to both gender-based violence as social problem, and interpersonal violence as pragmatic problem, both of which can be approached through the vehicle of self-defence practice; such as the ethnographic ground presented these to me.

However, recalling that taking up new practices into the habitus takes a period of years as opposed to months, I have attempted to argue throughout this thesis that while some self-defence techniques can be taken up quickly, the willingness to defend oneself in the first place is a body-habit that takes years of confidence-building to develop through shifting the way individuals approach their bodies: from 'aesthetic project', then through asking yourself what you can do with your body, and finally, through the often lengthy, repetitive process of learning individual techniques, learning what your body can endure and dish out.

Of course, this confidence in one's physical capabilities needs to work with something more amorphous - that is, one's emotive/affective capabilities, and these are learned somewhere between the repetition of physical techniques, and situational roleplay designed to trigger the sort of novelty that comes up in everyday life outside the dojo.

What self-defence does enable participants to do is experience vulnerability (and even violence) differently - where a threatening or violent event might have rendered a person unable to act out of shock or paralyzing fear, he or she might now have trained some capacity to withstand the shock of violence or threat and respond effectively to it. It 
seems that effectively responding to both violence and vulnerability starts there, as opposed to a specific physical or verbal technique learned over a few weeks, and perhaps this is why even picking up on or perfecting a few techniques will be effective - as they were for Jen.

Having explored the process of learning self-defence, however, I want to address feminist scholarship of self-defence as response to gender-based violence. Exploring the process of taking up new techniques or habits into the body should not be left out of analyses of the benefits of self-defence, whether the result is to tell young women the benefits they can realistically accrue, or to offer a caveat for young women seeking to learn self-defence in response to personal experiences of violence. They will learn some techniques, but they will need to practice regularly, have a safe space to do so, and may need more than a few weeks in which to learn. If the course is designed with women or gender-based violence in mind, they should also be offered the knowledge that 'selfdefence' does not always look like physical confrontation, but sometimes like conceding a point, or running away from a situation, or strategically complying with an aggressor in order to keep themselves safe. In other words, sometimes self-defence does not look so different from their own socialization - their natural, lived attitude. The difference, however, is in the newly deliberate, strategic attitude that takes up the 'compliant victim' stance for a reason - and with an exit strategy in mind.

Yet my critique runs deeper than the pragmatics of self-defence and its attendant caveats - it attends to the process of taking up a physical practice. Such practices call for attending to the body and its habits, to how living body-subject-selves learn. Ignoring how bodies learn when examining a physical practice such as self-defence or martial arts 
in response to violence and vulnerability is not responsible. The stakes are too high. There is one more critique, and it is one I have of my own work as well. However, it will be addressed as a question for further research. Given the timeframes of a Master's project, and given the relative constriction of having "only" effectively five months of fieldwork, I was surprised to find myself with more material - and more questions - than I could work with in the time I had.

\subsection{Questions for Further Research}

One of the questions that came up over the course of my research came out in the aggression-management training undertaken in the advanced class and could be phrased as: what are the dynamics between aggression/impression-management as performance and defending the socio-legal person after having to protect oneself from violence?

A question that came out of casual conversations outside of the classes referred to self-defence as a project taken up not just over concerns of gender-based violence or bullying, but concerns of race and class. Much of this project, in spite of my attempts to highlight certain aspects of self-defence literature and practice, was very much in the same stream as the literature I reviewed: I worked with white, middle-class men and women, and though I attempted to disrupt the unspoken narrative of 'white as default', it strikes me that further work is needed.

A question I started to ask but could not do justice to here: Is self-defence practice a taking-up of anxieties over race, class, and gender, using the narrative vehicle of 'violence on the streets'? 


\section{References}

American Anthropological Association

2009 AAA Style Guide.

http://www.aaanet.org/publications/style_guide.pdf

Accessed January 10, 2013

Angleman, Amy J., Yoshihiko Shinzato, Vincent B. Van Hasselt, Stephen A. Russo

2009 Traditional Martial Arts Versus Modern Self-Defence Training for

Women: Some Comments.

Aggression and Violent Behavior 14 (2009): 89-93.

Brecklin, Leanne R.

2008 Evaluation outcomes of self-defence training for women: A review In Aggression and Violent Behavior 13 (2008) 60-76.

2011 The Benefits of Self-Defence Training for Sexual Assault Survivors. In Surviving Sexual Violence: A Guide to Recovery and Empowerment. Thema Bryant-Davis, ed. Pp. 276-295. New York, Rowman \& Littlefield Publishers Inc.

Brecklin, Leanne R., Sarah E. Ullman

2004 Correlates of Post-Assault Self-defence/Assertiveness Training Participation For Sexual Assault Survivors. Psychology of Women Quarterly 28: 147-158.

2005 Self-Defence or Assertiveness Training and Women's Responses to Sexual Attacks. Journal of Interpersonal Violence 20(6): 738-762.

Burrow, Sylvia

2008 Bodily Limits to Autonomy: Emotion, Attitude, and Self-Defence.

In Embodiment and Agency. Sue Campbell, Letitia Meynell, and Susan Sherwin, eds. Pp. 126-142.

University Park, Pennsylvania State University Press.

Butler, Judith

1988 Performative Acts and Gender Constitution: An Essay in Phenomenology And Feminist Theory. Theatre Journal 40(4): 519-531.

1990 Gender Trouble: Feminism and the Subversion of Identity. London, Routledge.

Cermele, Jill A.

2004 Teaching Resistance to Teach Resistance: The Use of Self-defence in Teaching Undergraduates about Gender Violence. Feminist Teacher 15(1): 1-15. 


\section{Cohen, Einat Bar-On}

2007 Timing in Karate \& The Body in its Own Right.

Social Analysis. 51(3): 1-22.

2009 Kibadachi in karate: pain and crossing boundaries within the 'lived body' and within sociality. Journal of the royal Anthropological Institute (N.S.) 15: 610-629.

Collins, Randall

2008 Violence: A Microsociological Theory. Princeton NJ, Princeton University Press.

Csordas, Thomas

1993 Somatic Modes of Attention. Cultural Anthropology, 8(2): 135-156.

1999 The body's career in Anthropology. In Anthropological Theory Today. H. Moore (ed.). Cambridge, Polity Press: 172-205.

De Becker, Gavin

1997 The Gift of Fear and Other Survival Signals That Protect Us From Violence. New York, Dell Publishing.

De Grave, Marc

2011 The Training of Perception in Javanese Martial Arts.

In Martial Arts as Embodied Knowledge: Asian Traditions in a Transnational World. D.S. Farrer and John Whalen-Bridge, eds. Pp. 123141.

De Welde, Kristine

2003 Getting Physical: Subverting Gender through Self-Defence. Journal of Contemporary Ethnography. 32(3): 247-278.

Gee, Janet

1992 Cultivating the Senses for Optimal Self-Defense

In Women in the Martial Arts, Carol Wiley, ed. Pp. 77-81.

Berkeley, North Atlantic Books.

Goffman, Erving

1959 Presentation of Self in Everyday Life.

New York, Doubleday Anchor Books.

Hall, Rachel

2004 "It Can Happen To You": Rape Prevention in the Age of Risk Management. In Hypatia 19(3): 1-19. 
Hollander, Jocelyn A.

2004 'I Can Take Care of Myself': The Impact of Self-Defence Training on Women's Lives. Violence Against Women 10(3): 205-235.

2010 Why do Women Take Self-defence Classes? Violence Against Women 16(4): 459-478.

Jackson, Michael

1983 Thinking through the Body: An Essay on Understanding Metaphor. In

Social Analysis 14 (1983): 127-148.

1989 Paths Toward a Clearing: Radical Empiricism and Ethnographic Inquiry. Indianapolis, Indiana University Press.

Leder, Drew

1990 The Absent Body. Chicago, University of Chicago Press.

Leung, Debbie

1992 Martial Arts and Women's Self Defense: Two Perspectives.

In Women in the Martial Arts, Carol Wiley, ed. Pp. 66-72.

Berkeley, North Atlantic Books.

Loren, BK

2001 The Way of the River: Adventures and Meditations

Of a Woman Martial Artist. Guilford, The Lyons Press.

McCaughey, Martha

1997 Real Knockouts: The Physical Feminism of Women's Self-defence.

New York: New York University Press.

1998 The Fighting Spirit: Women's Self-defence Training and the Discourse of Sexed Embodiment. Gender and Society 12(3): 277-300.

McDaniel, Patricia

1993 Self-Defence Training and Women's Fear of Crime. Women's Studies Int. Forum 16(1): 37-45.

Merry, Sally Engle

2009 Gender Violence: A Cultural Perspective. Oxford: Wiley-Blackwell.

Merleau-Ponty, Maurice

2012 [1945] Phenomenology of Perception. Donald A. Landes, trans. Taylor \& Francis.

Paradis, Elise

2010 Bourdieu, Boxing, and Bodies: The Multidimensionality of Bodily

Capital. Society for the Study of Social Problems Conference, 2010. 
Riches, David

1986 The Phenomenon of Violence. In The Anthropology of Violence. David Riches, ed. New York, Basil Blackwell Inc. Pp. 3-27.

Samudra, Jaida Kim

2008 Memory in our body: Thick participation and the translation of kinesthetic experience. American Ethnologist 35(4): 665-681.

Sinha, Maire

2013 Measuring Violence Against Women: Statistical Trends. Juristat. Statistics Canada Catalogue no. 85-002-X. Maire Sinha, ed. Ottawa, Ontario. http://www.statcan.gc.ca/pub/85-002-x/2013001/article/11766eng.pdf (Accessed Jun 3, 2013)

Spencer, Dale

2012 Ultimate Fighting and Embodiment: Violence, Gender, and Mixed Martial Arts. New York: Routledge.

Stanko, Elizabeth

1988 Everyday Violence: How Women and Men Experience Sexual and Physical Danger. London, Pandora Press.

Stewart, Mary White

2002 Ordinary Violence: Everyday Assaults Against Women. Westport, Connecticut, Bergin \& Garvey.

Straus, Erwin

1963 The primary world of senses, a vindication of sensory experience. New York, Free Press of Glencoe.

1966 Phenomenological Psychology. New York, Basic Books.

Wacquant, Loïc

1995 The Pugilistic Point of View: How Boxers Think and Feel about Their Trade. Theory and Society 24 (4): 489-535.

1998 A Fleshpeddler at Work: Power, Pain, and Profit in the Prizefighting Economy. Theory and Society 21(1): 1-42.

2004 Body and Soul: Ethnographic Notebooks of An Apprentice Boxer. New York: Oxford University Press.

Waldenfels, Bernhard

2007 The Question of the Other. Albany, State University of New York Press. 